\title{
Elucidating the effect of impurities present in different crude glycerol sources on lipid and citric acid production by Yarrowia lipolytica SKY7
}

\author{
Lalit R Kumar ${ }^{\mathrm{a}^{*}}$, Sravan K Yellapu ${ }^{\mathrm{a}}$, Song Yan ${ }^{\mathrm{a}}$, RD Tyagi ${ }^{\mathrm{a}}$ \& Patrick Drogui ${ }^{\mathrm{a}}$ \\ aINRS-ETE, 490, Rue de la Couronne, Québec, Canada, G1K 9A9 \\ *Corresponding author: Email: lalit_r.kumar@ete.inrs.ca
}

\begin{abstract}
BACKGROUND: Crude glycerol is an industrial by-product of biodiesel producing companies and requires high cost for purification. In fact, it is a good carbon source and can be used for lipid production from oleaginous microbes. However, crude glycerol has several impurities which may impact the cellular metabolism for lipid production.

RESULTS: In this study, crude glycerol from different sources was employed for lipid production and its impurities' effect on the biomass and lipid production was investigated on Yarrowia lipolytica SKY7, which is a well-known yeast for lipid and citric acid production. Growth inhibition was observed in BIOCARDEL, BIOLIQ and ROTHSAY glycerol when compared with pure glycerol. This was due to high sodium concentration in BIOCARDEL, high potassium concentration in BIOLIQ and high sulphur concentrations in ROTHSAY glycerol. Among three crude glycerol sources, the highest lipid concentration (14.78 $\mathrm{g} / \mathrm{L})$ was obtained using BIOCARDEL glycerol at $96 \mathrm{~h}$. However, the higher citric acid concentration of $18.70 \mathrm{~g} / \mathrm{L}$ in ROTHSAY glycerol and $12.00 \mathrm{~g} / \mathrm{L}$ in BIOLIQ was obtained at $96 \mathrm{~h}$ when compared with $8.30 \mathrm{~g} / \mathrm{L}$ in BIOCARDEL glycerol.
\end{abstract}

CONCLUSION: High potassium and sulphur concentration in glycerol medium inhibits cell growth and lipid production in Yarrowia lipolytica SKY7 while favors citric acid production.

This article has been accepted for publication and undergone full peer review but has not been through the copyediting, typesetting, pagination and proofreading process which may lead to differences between this version and the Version of Record. Please cite this article as doi: $10.1002 /$ jctb.6531

This article is protected by copyright. All rights reserved. 
Keywords: Fermentation, Lipids, Biochemistry, Biochemical engineering, Biodiesel 


\section{Introduction}

Biodiesel is a renewable, non-toxic, and biodegradable fuel that is produced mainly from vegetable oils ${ }^{1}$. The increasing price of edible oil and limited feedstock sources have led to biodiesel production unfeasible. Food crops like rapeseed, jatropha and canola are used for biodiesel production, but they have disadvantages like dependency on land and climatic conditions, removal of rain forest, high labour and energy intensive process ${ }^{2}$. The microbial lipid (also known as microbial oil) can be quickly synthesized in microbial cells, which has capacity for lipid accumulation over $20 \%(\mathrm{w} / \mathrm{w})^{3,4}$. Moreover, fatty-acid composition of microbial lipid is similar to that of vegetable oil ${ }^{5}$. Renewable and cheap carbon sources are being explored for lipid production to reduce its production cost ${ }^{6-9}$. Therefore, crude glycerol has drawn researcher's attention in past years for lipid production as it is a by-product containing numerous complex impurities, and produced in large quantities ${ }^{10,11}$.

However, crude glycerol has several impurities depending on the process used for transesterification. For instance, when the base catalyst $(\mathrm{NaOH})$ was used for biodiesel production, the molar methanol to oil ratio generally varied between 5:1-10:1 and the catalyst concentration was $1 \%-1.5 \% \mathrm{w} / \mathrm{w}$ of the oil weight ${ }^{12}$. Hence, the crude glycerol obtained after trans-esterification contained glycerol (40\%-50\%), methanol (20\%-40\%), water (10\%-15\%), sodium salt of fatty acid (0.5\%-2\%), fatty acid esters $(0.5 \%-2 \%)$ and sodium chloride $(0.5 \%-2 \%)$ under the abovementioned conditions. Meanwhile, when the acid catalyst $\left(\mathrm{H}_{2} \mathrm{SO}_{4}\right)$ was used to produce biodiesel, 
the molar methanol to oil ratio used generally varied between $7: 1-12: 1$, and the catalyst concentration was $5 \%-10 \% \mathrm{w} / \mathrm{w}$ of the oil weight ${ }^{13}$. The crude glycerol solution obtained under such conditions consists of glycerol (35\%-40\%), methanol (30\%-50\%), water (20\%-30\%) and sulphuric acid (5\%-10\%). The impurities like methanol, soap, fatty acid esters, and catalyst in the crude glycerol affect biomass and lipid production by oleaginous microbes ${ }^{14}$.

Many studies have been conducted on the effect of $\mathrm{NaOH}$, methanol, soap and free-fatty acids (FFAs) on cell growth and lipid production using different microbes like Trichosporon oleaginosus, Rhodosporidium toruloides and Schizochytrium limacinum ${ }^{14-17}$. However, the effect of chemical elements present in the crude glycerol on biomass and lipid accumulation has not been reported on Y. lipolytica SKY7. The present study was conducted using three different crude glycerols obtained from different biodiesel producing companies - ROTHSAY, BIOCARDEL and BIOLIQ. These companies adopt different trans-esterification processes and as a result, they produce crude glycerol solution containing different impurities. Therefore, the objective of this study was to investigate the effect of various impurities present in the crude glycerol on lipid and citric acid (CA) production by Y. lipolytica SKY7. The study directly used crude glycerol without purification and could help the biodiesel industry in recycling their crude glycerol produced.

\section{Materials and methods}




\subsection{Materials}

\subsubsection{Crude glycerol characterization}

Crude glycerol was collected from biodiesel production industries in Quebec, Canada ROTHSAY, BIOCARDEL and BIOLIQ and then stored at room temperature $\left(25^{\circ} \mathrm{C}\right)$. Physicochemical characteristics for glycerol was evaluated (Table 1). Density, pH, glycerol, soap, water and methanol content in each crude glycerol was estimated ${ }^{18}$. Elemental concentration in crude glycerol samples was determined by inductively coupled plasma mass spectroscopy (ICPMS) after acid digesting the crude glycerol samples.

\subsubsection{Strain}

Yarrowia lipolytica SKY7 isolated in INRS laboratory was employed in the study ${ }^{19}$.

\subsection{Lipid and CA production using different types of crude glycerol}

\subsubsection{Pre-culture and inoculum preparation}

The dormant pure culture of $Y$. lipolytica stored in the refrigerator $\left(4^{\circ} \mathrm{C}\right)$ was revived by cultivating in pre-culture 1 (or PC1) synthetic media (Yeast extract, peptone, dextrose broth/ YPD: $20 \mathrm{~g} / \mathrm{L}$ glucose, $20 \mathrm{~g} / \mathrm{L}$ peptone and $10 \mathrm{~g} / \mathrm{L}$ yeast extract) in shaking incubator with agitation 180 rpm and the temperature of $28^{\circ} \mathrm{C}$ for $24 \mathrm{~h}$. PC1 volume of $6.25 \% \mathrm{v} / \mathrm{v}$ (as inoculum) was used to 
produce pre-culture 2 (PC2). Pre-culture 2 was prepared in a medium containing individual crude glycerol (equivalent to $5 \mathrm{~g}$ carbon /L) fortified with YPD. PC2 was grown at $180 \mathrm{rpm}$ and $28^{\circ} \mathrm{C}$ for $36 \mathrm{~h}$ before being transferred to the production fermenter.

\subsubsection{Fed-batch fermentation}

2.2.2.1 Media preparation: The fermenters were operated under fed-batch mode to avoid both substrate limitation. Besides 3 different crude glycerol sources, pure glycerol was used as the control run. Each fermenter started with $10-13 \mathrm{~g} / \mathrm{L}$ carbon, and $\mathrm{C} / \mathrm{N}$ ratio of 10 . Since BIOCARDEL glycerol contains soap, $98.7 \%$ of soap was converted to free fatty acids (FFA) by adjusting $\mathrm{pH}$ to 5.0 for 30 min before being used in fermentation ${ }^{18}$. The soap was converted to FFA to minimize growth inhibition from high soap concentration ${ }^{17}$. FFA and glycerol concentration in BIOCARDEL were converted to equivalent carbon concentration. For pure glycerol, BIOLIQ and ROTHSAY glycerol, glycerol concentration was converted to equivalent carbon concentration. Medium of each fermenter was supplemented with minerals at $0 \mathrm{~h}$ containing (g/L): $2.7 \mathrm{KH}_{2} \mathrm{PO}_{4}, 0.95 \mathrm{Na}_{2} \mathrm{HPO}_{4}, 0.2 \mathrm{MgSO} \cdot 7 \mathrm{H}_{2} \mathrm{O}, 0.04 \mathrm{CaCl}_{2} .2 \mathrm{H}_{2} \mathrm{O}, 0.0055$ $\mathrm{FeSO}_{4} .7 \mathrm{H}_{2} \mathrm{O}, 0.001 \mathrm{ZnSO}_{4} .7 \mathrm{H}_{2} \mathrm{O}$ and $0.00076 \mathrm{MnSO}_{4} \cdot \mathrm{H}_{2} \mathrm{O}$ at the beginning of fermentation.

\subsubsection{Fermentation operation}

This article is protected by copyright. All rights reserved. 
Fermentation was carried out in a stirred tank fermenter (SARTORIUS BIOSTAT and INFORS AG Fermenter) equipped with accessories and programmable logic control (PLC) system for dissolved oxygen (DO), $\mathrm{pH}$, anti-foam, impeller speed, aeration rate and temperature. The software allowed automatic set-point control and integration of all parameters via PLC. Before each sterilization cycle, the polarographic pH-electrode (Mettler Toledo, USA) and oxygen probe were calibrated. Subsequently, fermenters were charged with fermentation nutrient medium and sterilized. PC2 of $6.25 \%(\mathrm{v} / \mathrm{v})$ was transferred to the fermenter ${ }^{2}$ and fermentation was started.

During initial 12 h, DO decreases from $90 \%$ to $35 \%$ and later it was maintained in the range of $25 \%-40 \%$. The limitation of DO favors lipid production ${ }^{20}$. DO was maintained between $25-$ $40 \%$ saturation by adjusting the agitation rate $(300-600 \mathrm{rpm})$ and air flow rate $(1.3-2.5 \mathrm{~L} / \mathrm{min})$. The temperature was maintained at $28^{\circ} \mathrm{C}$ by circulating water through the fermenter jacket. Fermentation $\mathrm{pH}$ was controlled automatically at $6.5 \pm 0.1$ through computer-controlled peristaltic pumps by the addition of $\mathrm{pH}$ control agents: $4 \mathrm{M} \mathrm{NaOH} / 4 \mathrm{M} \mathrm{H}_{2} \mathrm{SO}_{4}$. $\mathrm{pH}$ of 6.5 was selected as it has been reported optimum for lipid and citric acid production ${ }^{21}$.

2.2.2.3 Fed-batch strategy: Each fermenter was started as a batch fermentation with 10-13 g/L carbon concentration, and $\mathrm{C} / \mathrm{N}$ ratio of 10 . When carbon concentration in the medium went below $2 \mathrm{~g} / \mathrm{L}$, a carbon feed was added to make up the carbon concentration to initial concentration. Nitrogen was added in the beginning of fermentation through peptone and was not added in subsequent feed. The reason for it is that high initial nitrogen concentration or low initial $\mathrm{C} / \mathrm{N}$ ratio 
will help in build of high biomass (lipid free) during early stages of fermentation and once nitrogen concentration will become limiting, the addition of glycerol feed will increase $\mathrm{C} / \mathrm{N}$ ratio in the medium resulting in high lipid accumulation. Feeding details for different glycerol sources have been provided in Table 2a. All fermentations were conducted for $96 \mathrm{~h}$. Samples were withdrawn after every $8 \mathrm{~h}$ to determine the biomass, lipid, FFA, glycerol and organic acids in the sample.

\subsection{Impact of high concentration of elements on biomass, lipid and CA production}

To investigate the effect of high concentration of $\mathrm{Na}, \mathrm{K}, \mathrm{S}$ on biomass, lipid and $\mathrm{CA}$, shake flask study was conducted. The dormant pure culture of $Y$. lipolytica $\left(4^{\circ} \mathrm{C}\right)$ was revived by cultivating in pre-culture (PC) synthetic media (Yeast extract peptone dextrose broth/ YPD: 20 g/L glucose, $20 \mathrm{~g} / \mathrm{L}$ peptone and $10 \mathrm{~g} / \mathrm{L}$ yeast extract) for $24 \mathrm{~h}$ in a shaking incubator with agitation $180 \mathrm{rpm}$ and temperature of $28^{\circ} \mathrm{C}$. PC volume of $6.25 \% \mathrm{v} / \mathrm{v}$ was used for inoculation of experimental flasks. Experiments were carried out in duplicate in $1 \mathrm{~L}$ Erlenmeyer flask with a working volume of $300 \mathrm{~mL}$. All experimental shake flasks contained: $30 \mathrm{~g} / \mathrm{L}$ pure glycerol, 2.5 g/L peptone, $2.7 \mathrm{~g} / \mathrm{L} \mathrm{KH}_{2} \mathrm{PO}_{4}, 0.95 \mathrm{~g} / \mathrm{L} \mathrm{Na} \mathrm{HPO}_{4}, 0.2 \mathrm{~g} / \mathrm{L} \mathrm{MgSO} \cdot 7 \mathrm{H}_{2} \mathrm{O}, 0.04 \mathrm{~g} / \mathrm{L} \mathrm{CaCl}_{2} .2 \mathrm{H}_{2} \mathrm{O}$, $0.0055 \mathrm{~g} / \mathrm{L} \mathrm{FeSO}_{4} .7 \mathrm{H}_{2} \mathrm{O}, 0.001 \mathrm{~g} / \mathrm{L} \mathrm{ZnSO}_{4} .7 \mathrm{H}_{2} \mathrm{O}$ and $0.00076 \mathrm{~g} / \mathrm{L} \mathrm{MnSO}_{4} \cdot \mathrm{H}_{2} \mathrm{O}$ at $0 \mathrm{~h}$. In shake flask 2, additional $\mathrm{Na}$ was added in the medium through $\mathrm{NaCl}$ so that the final concentration of $\mathrm{Na}$ in the medium was $8.3 \mathrm{~g} / \mathrm{L}$ at $0 \mathrm{~h}$. In shake flask 3, additional $\mathrm{K}$ was added in the medium through $\mathrm{KCl}$ so that the final concentration of $\mathrm{K}$ in the medium was $6.32 \mathrm{~g} / \mathrm{L}$ at $0 \mathrm{~h}$. In shake flask 4 , additional $\mathrm{S}$ was added through $\mathrm{H}_{2} \mathrm{SO}_{4}$ so that the final concentration of $\mathrm{S}$ in the medium was 4 
$\mathrm{g} / \mathrm{L}$. Initial $\mathrm{pH}$ was 6.5 but the $\mathrm{pH}$ was not controlled in shake-flasks. The flasks were incubated at $180 \mathrm{rpm}$ and $28^{\circ} \mathrm{C}$ for $96 \mathrm{~h}$. The samples were withdrawn every $24 \mathrm{~h}$ for biomass, lipid CA and glycerol analysis.

\subsection{Analytical Techniques}

Biomass: Ten milliliters of each sample was centrifuged at $8000 \mathrm{rpm}$. The supernatant was collected and stored at $4^{\circ} \mathrm{C}$ to determine glycerol concentration. The resulting biomass pellet was washed with distilled water until a clear supernatant was obtained. The biomass obtained was then transferred to a pre-weighed aluminum cup, and dried at $80^{\circ} \mathrm{C}$ to a constant weight. The biomass concentration was calculated based on the weight difference between the aluminum cup with and without containing biomass.

Lipid concentration: To determine the lipid concentration, a $10 \mathrm{~mL}$ sample of fermentation broth was centrifuged at $9000 \mathrm{~g}$ for 15 minutes and the pellet obtained was washed twice with distilled water to remove residual glycerol. The pellet was subjected to overnight drying at $80^{\circ} \mathrm{C}$. The dry solid pellet was mixed with $15 \mathrm{~mL}$ of the mixture of chloroform and methanol $(2: 1 \mathrm{v} / \mathrm{v})$ in a 50 $\mathrm{mL}$ tube, which was subjected to heating at $60^{\circ} \mathrm{C}$ in an agitated water bath for $4 \mathrm{~h}$. After shaking and centrifugation at $6000 \mathrm{rpm}$ for 20 minutes, the upper layer (lipid dissolved in chloroform) was collected after centrifugation, and filtered. The filtrate was collected. In the second extraction, 15 
$\mathrm{mL}$ of a mixture of chloroform and methanol $(2: 1 \mathrm{v} / \mathrm{v})$ was added to the tube containing the residual biomass and beads, and the solution was kept in an agitated water bath at $60^{\circ} \mathrm{C}$ for $4 \mathrm{~h}$, and same steps were repeated. The filtrates from the first and the second extraction were mixed. The filtrate layer was subjected to solvent evaporation. The lipid concentration was analyzed by the following formulae ${ }^{22}$ :

$$
\text { Lipid concentration }(g / L)=\frac{W a-W b}{S S x V} \text { (1) }
$$

where $\mathrm{W}_{\mathrm{a}}=$ weight of glass tube after evaporation, $\mathrm{W}_{\mathrm{b}}=$ weight of empty glass tube, $\mathrm{SS}=$ suspended solids concentration $(\mathrm{g} / \mathrm{L}), \mathrm{V}=$ volume of fermented broth taken for lipid extraction

Glycerol: Glycerol was measured according to Bondioli and Della Bella ${ }^{23}$.

FFA: A sample of $0.5 \mathrm{~mL}$ was taken for FFA estimation and few drops of phenolphthalein indicator added to $10 \mathrm{~mL}$ of isopropanol in a beaker agitated with a magnetic bar. Titration was conducted against $0.01 \mathrm{~N} \mathrm{NaOH}$ until the colour of the solution changed to pink. FFA content was calculated as per following formulae:

$$
F F A \text { content }(\%)=28.2 \times N \times \frac{V-B}{W} \times 100(2 a)
$$

Multiplying FFA content with density of the sample $(1000 \mathrm{~g} / \mathrm{L})$ will give the result in $\mathrm{g} / \mathrm{L}$.

$$
\text { FFA }\left(\frac{g}{L}\right)=\text { FFA content }(\%) x \frac{1000}{100}
$$


where $\mathrm{V}=$ the volume in $\mathrm{mL}$ of the $\mathrm{NaOH}$ solution $(0.01 \mathrm{~N})$ used in titration; $\mathrm{B}=$ the volume in $\mathrm{mL}$ of the blank used titration solution; $\mathrm{N}=$ the normality of the titration solution; $\mathrm{W}=$ the weight of the sample in grams.

Organic Acids: Organic acids (citric acid, keto-glutamic acid, pyruvic acid) in the supernatant of the samples were analyzed using LC-MS-MS (Liquid chromatography-mass spectrometry).

Elemental concentration in samples were determined by inductively coupled plasma mass spectroscopy (ICP-MS) after acid digesting the samples (model DRE, Leeman Labs Inc).

All samples were analyzed in duplicates and their standard deviation was less than 5\%.

\subsection{Determination of kinetic parameters}

Productivity is defined as g product produced per unit volume at a particular time t. Unit of productivity is g/L/h. Lipid and citric acid productivity will be calculated by equation 3.

$$
\text { Productivity }\left(\frac{g}{\text { L.h }}\right)=\frac{\text { product produced }(g)}{(\text { Volume } x \text { time })}
$$

Biomass yield coefficient (Yx/s) is defined as g of biomass produced per g of substrate consumed. Biomass yield will be determined by the equation (4):

$$
Y_{X} / s=d X / d S(4)
$$


Product yield coefficient (Y $\mathrm{Y} / \mathrm{s})$ is defined as the amount of product produced per g of substrate consumed. Its will be determined for lipid and citric acid by the equation (5a) and (5b):

$$
\begin{aligned}
& Y_{l / S}=d L / d S \\
& Y c / s=d C / d S \quad(5 b)
\end{aligned}
$$

Since BIOCARDEL glycerol had free fatty acids (FFA) and glycerol. These two substrates were converted to equivalent carbon and the sum of the carbon consumed was used to calculate all yield coefficients.

Specific growth rate $\left(\mu, \mathrm{h}^{-1}\right)$ was determined by the equation (6):

$$
\mu=d X /(X . d t) \quad(6)
$$

Where $\mathrm{X}$ represents biomass concentration at particular time $\mathrm{t}$

Biomass yield, productivity and specific growth rate have been calculated with respect to cell biomass including intracellular lipid.

\subsection{Lipid characterization}


A lipid sample of $25 \mathrm{mg}$ was trans-esterified using acidified methanol. Decahexanoic acid was used as the internal standard. The trans-esterified lipid fraction was extracted using hexane and the samples were further characterized by GC (Agilent 7890B) equipped with flame ionization detector. Column length was $60 \mathrm{~m}$ (Agilent J\&W); the carrier gas was helium at a flow rate of 1.18 $\mathrm{mL} / \mathrm{min}$ with the oven temperature $230^{\circ} \mathrm{C}$. Trans-esterified sample $(1 \mu \mathrm{L})$ was injected with an automated sample injector and the sample analysis was performed with Agilent GC chem station software. A 37 components FAME mixture from Supelco was used as the calibration standard at different concentrations.

\section{Results}

\subsection{Characterization of crude glycerol}

The composition of different crude glycerol solutions is presented in Table 1. In ROTHSAY, $\mathrm{NaOH}$ was used as catalyst in trans-esterification process and $\mathrm{H}_{2} \mathrm{SO}_{4}$ was used to treat the excess $\mathrm{NaOH}$ present in crude biodiesel. Due to use of $\mathrm{H}_{2} \mathrm{SO}_{4}$, $\mathrm{pH}$ of ROTHSAY glycerol was 2.5 and sulphur concentration was high (11.00 g/L). In BIOLIQ, potassium concentration (70.84 g/L) was the highest because potassium methoxide was used as the catalyst in the transesterification reaction. Due to the use of potassium methoxide, $\mathrm{pH}$ of BIOLIQ glycerol was 14. In BIOCARDEL, sodium concentration (12.80 g/L) was the highest as $\mathrm{NaOH}$ was used as the catalyst during trans-esterification reaction and due to which, $\mathrm{pH}$ of BIOCARDEL glycerol was 9. 


\subsection{Lipid and CA production using different types of crude glycerol (fed-batch fermentation)}

\subsubsection{Biomass production}

Among three crude glycerol sources, the maximum biomass $(38.10 \mathrm{~g} / \mathrm{L})$ concentration was observed in BIOCARDEL followed by BIOLIQ (20.36 g/L) and ROTHSAY (12.65 g/L) glycerol at $96 \mathrm{~h}$ (Figure 1a). The surfactant and emulsifying nature of FFA (present in BIOCARDEL glycerol) increased cell membrane permeability of the culture medium and improved the nutrientintake capability of $Y$. lipolytica ${ }^{14}$. This might have improved growth and the final biomass concentration. Also, before the fermentation, soap was converted to free fatty acids (using $\mathrm{pH}$ adjustment) which were readily used by micro-organisms ${ }^{17,}{ }^{24}$. However, biomass concentration in BIOCARDEL was less than pure glycerol (54.27 g/L) at $96 \mathrm{~h}$. Higher concentration of sodium present in BIOCARDEL glycerol had a slightly negative impact on biomass concentration as biomass concentration in BIOCARDEL glycerol was 70\% of that obtained in pure glycerol. This is evident from Table $2 \mathrm{~b}$ that maximum sodium concentration in pure glycerol was $3.72 \mathrm{~g} / \mathrm{L}$ (64 h) while maximum sodium concentration in BIOCARDEL glycerol was $8.30 \mathrm{~g} / \mathrm{L}$ (64 h).

Lower concentration of biomass $20.36 \mathrm{~g} / \mathrm{L}$ in BIOLIQ and $12.65 \mathrm{~g} / \mathrm{L}$ in ROTHSAY glycerol was observed at $96 \mathrm{~h}$. It could be due to higher potassium concentration in the BIOLIQ glycerol medium and higher concentration of sulphur and undetected residual charcoal present in ROTHSAY glycerol medium in the beginning of the fermentation medium. It was also observed 
that the potassium concentration in BIOLIQ glycerol and sulphur concentration in ROTHSAY kept on increasing with feed indicating that organism was not using them. Consequently, it resulted in lower final biomass concentration (at $96 \mathrm{~h}$ of fermentation) in BIOLIQ and ROTHSAY glycerol respectively, which was almost $38 \%$ and $23 \%$ of the biomass obtained in pure glycerol. After imparting $1^{\text {st }}$ feed in BIOLIQ (24 h) and ROTHSAY glycerol (32 h), cell growth nearly ceased.

\subsubsection{Carbon consumption}

Carbon concentration in the medium for different glycerol sources is indicated by Figure 1b while Figure 1c indicates carbon consumption during the process for different glycerol sources. As mentioned above, a high potassium and sulphur concentration present in BIOLIQ and ROTHSAY glycerol might have proved inhibitory for microbial growth due to which slower substrate consumption was observed and lesser number of feeds were required (Table 2a). When carbon concentration in the medium reached $<2 \mathrm{~g} / \mathrm{L}$, additional glycerol feed was added during the fermentation employing BIOLIQ and ROTHSAY glycerol media at $24 \mathrm{~h}$ and $32 \mathrm{~h}$, respectively (Figure 1b), which further increased potassium and sulphur concentration in the medium to 6.32 and $4.02 \mathrm{~g} / \mathrm{L}$, respectively. Thus, a very high concentration of potassium and sulphur in BIOLIQ and ROTHSAY might have led to further inhibition of cell growth after the feed and hence lower carbon consumption. Maximum carbon concentration $51.67 \mathrm{~g} / \mathrm{L}$ consumed in $96 \mathrm{~h}$ fermentation was observed for BIOCARDEL glycerol, while $26.61 \mathrm{~g} / \mathrm{L}$ and $16.24 \mathrm{~g} / \mathrm{L}$ carbon was consumed in case of BIOLIQ and ROTHSAY, respectively (Figure 1c). 


\subsubsection{Lipid production}

Among 3 crude glycerol media, the lipid concentration of $14.78 \mathrm{~g} / \mathrm{L}$ was observed in BIOCARDEL glycerol followed by $7.21 \mathrm{~g} / \mathrm{L}$ in BIOLIQ and $4.60 \mathrm{~g} / \mathrm{L}$ in ROTHSAY glycerol, respectively, at $96 \mathrm{~h}$ (Figure 2a). In case of BIOCARDEL glycerol, the lipid production started from the beginning of the fermentation. Higher lipid concentration in BIOCARDEL is due to the presence of free fatty acids in the medium (generated from soap). Y. lipolytica is utilizing FFA (hydrophobic substrate) and glycerol as carbon source for lipid production. Lipid production from hydrophobic substrates by oleaginous microbes follow ex-novo lipid accumulation ${ }^{25}$. Hydrophobic substrates get transferred inside the microbial cell by means of active transport. In order to transfer these hydrophobic substrates from the medium to inside the cell, $Y$. lipolytica can generate protrusions (structural changes on the surfaces of cells), which increases the contact surface between the yeast and substrates ${ }^{26}$. Inside the microbial cell, fatty acids are then either used for cell propagation or transformed to new fatty acid profiles ${ }^{25}$. During ex novo lipid accumulation process, cellular lipids are accumulated and, at the same time, lipid-free biomass is generated. Therefore, the above-mentioned biochemical process is a perfectly growth-associated anabolic activity and is independent of nitrogen concentration in the medium ${ }^{26}$. While lipid production from glycerol is de-novo lipid accumulation and is depend on nitrogen concentration in the medium. 
BIOCARDEL has FFA and glycerol as a carbon source while BIOLIQ and ROTHSAY only have glycerol as a carbon source. For BIOLIQ and ROTHSAY glycerol, lipid produced was lower than that of BIOCARDEL glycerol and was attributed to a lower biomass production in BIOLIQ and ROTHSAY glycerol, which in turn caused by inhibition due to a higher potassium and sulphur concentration present in the medium, respectively.

Lipid profile for different glycerol sources has been highlighted in Table 3. Palmitic acid (C16:0), C18:1 (Oleic acid) and C18:2 (Linoleic acid) were produced in every glycerol medium. Oleic acid (C18:1) and linoleic acid (C18:2) are the major components in the case of SKY7 ${ }^{\text {19, } 21 .}$ These lipids have the resemblance with the vegetable oil. The presence of polyunsaturated fatty acids (PUFAs) makes the isolate (Y. lipolytica) important for biodiesel production. The pure glycerol medium was higher in C14:0 (mystiric acid) and C16:0 (palmitic acid) which are phospholipids derived from the cell membrane while unsaturated fatty acids indicate cytosolic lipids. Highest fraction of PUFAs was obtained in BIOCARDEL glycerol followed by BIOLIQ, pure glycerol and ROTHSAY.

\subsubsection{Organic acids production}

The major organic acid produced was citric acid in this study. Y. lipolytica is a well-known industrial scale citric acid producer ${ }^{2}$. Citric-acid has applications in pharmaceutical and food industries besides detergents, cleaning products and toiletries. Figure $2 \mathrm{~b}$ showed citric acid 
production using different glycerol sources. The citric acid production (citrate concentration in the cytoplasm) is one of the important factors that control the lipid accumulation ${ }^{27}$. Citrate is known as the acetyl donor for fatty acid biosynthesis and is transported from mitochondria to the cytoplasm. A constant supply of intracellular citrate will generate adequate amounts of acetyl-CoA in the cytoplasm by the enzyme ACL (ATP citrate lyase). Acetyl CoA is converted to malonylCoA (a step-in lipid synthesis) using ACC enzyme (acetyl-CoA carboxylase) ${ }^{21}$. Lower nitrogen concentration in cultivation medium is responsible for lipid and citric acid production. Citric acid concentration was $3.90 \mathrm{~g} / \mathrm{L}, 8.30 \mathrm{~g} / \mathrm{L}, 12.00 \mathrm{~g} / \mathrm{L}$ and $18.74 \mathrm{~g} / \mathrm{L}$ in pure glycerol, BIOCARDEL, BIOLIQ and ROTHSAY, respectively, at $96 \mathrm{~h}$ (Figure 2b).

Usually, citric acid production takes place at C/N ratio greater than 100 for $Y$. lipolytica ${ }^{2}$. However, in ROTHSAY and BIOLIQ glycerol, the citric acid production took place even at lower $\mathrm{C} / \mathrm{N}$ ratios (Table 2b). Higher citric acid concentration in ROTHSAY and BIOLIQ glycerol could be due to the fact that metabolism was shifted towards citric acid production instead of lipid production. It has been reported that the higher potassium concentration in the media had a positive effect on the citric acid production ${ }^{28}$. High concentration of sulphur in ROTHSAY medium (3.70$4.02 \mathrm{~g} / \mathrm{L})$ and high potassium concentration in BIOLIQ glycerol (4.80-8.42 $\mathrm{g} / \mathrm{L})$ might have enhanced the citric acid production. This is also evident from the fact that $3.90 \mathrm{~g} / \mathrm{L}$ citric acid was produced in a pure glycerol medium where potassium and sulphur concentration were $1.43 \mathrm{~g} / \mathrm{L}$ and $0.30 \mathrm{~g} / \mathrm{L}$ (imparted from additional trace elements) at $0 \mathrm{~h}$. Every feed addition, increased the 
potassium and sulphur concentration in BIOLIQ and ROTHSAY glycerol media, which further increased the citric acid production in BIOLIQ and ROTHSAY medium. High concentration of sulphur and potassium in the media might have inhibited ATP-citrate lyase (ACL) required for breakdown of citrate. Due to inhibition of ACL, accumulated citrate in cytoplasm comes out of the cell instead of being converted to lipids ${ }^{21}$. In BIOCARDEL glycerol, lipid concentration and biomass concentration were higher when compared to other two glycerol sources as hydrophobic substrates (free fatty acids) are used via ex-novo lipid accumulation pathway. Since majority of carbon source is used for lipid and biomass concentration, hence citric acid production was lower in BIOCARDEL glycerol as compared to the other two glycerol sources.

Other organic acids produced during this study were pyruvic acid, alpha-ketoglutaric acid, malic acid, glutamic acid and fumaric acid (Table 4). Pyruvic acid, malic acid and alpha-ketoglutaric acid are intermediates of citric acid cycle and all have commercial applications ${ }^{29}$. Pyruvic acid is used as a weight-loss supplement, malic acid is used as food additive while alpha-keto glutaric acid is used for immune regulation and as anti-oxidant.

\subsubsection{Variation of biomass, lipid and citric acid productivities}

In order to calculate biomass productivity, the biomass curve can be divided in different sections (Table 5) and each section is represented by a straight line. The slope of each line 
represents biomass productivity (dX/dt) during that fermentation period. Lipid productivity (dL/dt), citric acid productivity (dC/dt) and carbon consumption rates (dS/dt) have been calculated by similar method.

In pure glycerol medium, lag phase was observed during 0-8 h (Figure 1a). Hence, biomass productivity has been accounted from $8 \mathrm{~h}$ onwards for pure glycerol medium (Table 5). Biomass productivity was higher during initial 24 h (pure glycerol, BIOLIQ and ROTHSAY) or initial 32 $\mathrm{h}$ (BIOCARDEL) than later period of fermentation (Table 5). Higher biomass productivity during initial 24-32 $\mathrm{h}$ is due to abundance of nitrogen and nutrients, which result in cell growth. Also, during the initial 24-32 h, carbon of peptone (contains 10\% carbon) was also used for cell growth. During later phase, biomass productivity was lower due to reduction in nutrients (pure glycerol) or inhibition in other 3 glycerol types due to feed addition. Highest biomass productivity was observed in pure glycerol followed by BIOCARDEL, BIOLIQ and ROTHSAY glycerol indicated that there was inhibition in BIOCARDEL, BIOLIQ and ROTHSAY. At $96 \mathrm{~h}$, the overall biomass productivity for pure glycerol, BIOCARDEL, BIOLIQ and ROTHSAY were $0.56 \mathrm{~g} / \mathrm{L} / \mathrm{h}, 0.40$ $\mathrm{g} / \mathrm{L} / \mathrm{h}, 0.21 \mathrm{~g} / \mathrm{L} / \mathrm{h}$ and $0.13 \mathrm{~g} / \mathrm{L} / \mathrm{h}$, respectively.

Irrespective of glycerol source, lipid productivity was higher during initial 16-24 h period because during this period, membrane lipids develop with biomass growth ${ }^{2}$. While during later stages of fermentation, lipid was accumulated as intracellular lipids in cytosol. For ROTHSAY 
and BIOLIQ, two sections are identified where membrane lipids are developed ( $1^{\text {st }}$ section, 0-16 h) and lipids accumulate in cytosol $\left(2^{\text {nd }}\right.$ section, 16-96h) (Table 5). For BIOCARDEL and pure glycerol, three sections were identified: $1^{\text {st }}$ section (accumulation of membrane lipids), $2^{\text {nd }}$ and $3^{\text {rd }}$ section (accumulation of cytosol lipids). However, $3^{\text {rd }}$ section had higher lipid productivity than $2^{\text {nd }}$ section due to higher $\mathrm{C} / \mathrm{N}$ ratio (Table $2 \mathrm{~b}$ ). At $96 \mathrm{~h}$, the overall lipid productivity for pure glycerol, BIOCARDEL, BIOLIQ and ROTHSAY were $0.184 \mathrm{~g} / \mathrm{L} / \mathrm{h}, 0.154 \mathrm{~g} / \mathrm{L} / \mathrm{h}, 0.075 \mathrm{~g} / \mathrm{L} / \mathrm{h}$ and $0.05 \mathrm{~g} / \mathrm{L} / \mathrm{h}$, respectively. Among three crude glycerol sources, lipid productivity was the highest in BIOCARDEL, followed by BIOLIQ and ROTHSAY. High lipid productivity in BIOCARDEL glycerol was due to ex novo lipid accumulation.

For 3 crude glycerol sources, citric acid productivities were lower during initial $24 \mathrm{~h}$ and was higher during late stages of fermentation (24-96 h). Citric acid productivities were higher during 24-96 h due to a reduction in nitrogen concentration and increase in the $\mathrm{C} / \mathrm{N}$ ratio in the medium. Citric acid productivity was the highest for ROTHSAY followed by BIOLIQ, BIOCARDEL and pure glycerol. Citric acid productivities were higher in ROTHSAY and BIOLIQ glycerol due to inhibition of ATP-citrate lyase enzyme responsible for the breakdown of intracellular citrate. Pure glycerol had lowest citric acid productivities as no additional element was present in the medium (only required trace elements were added). At $96 \mathrm{~h}$, the overall lipid productivity for BIOCARDEL, BIOLIQ and ROTHSAY were $0.086 \mathrm{~g} / \mathrm{L} / \mathrm{h}, 0.125 \mathrm{~g} / \mathrm{L} / \mathrm{h}$ and 0.195 g/L/h, respectively. 


\subsubsection{Variation of biomass, lipid and citric acid yield coefficients}

Point yields have been calculated by diving point productivity with glycerol consumption rate (calculated from Table 5) at particular point of time. Point lipid yield and point citric yields are depicted in Figure 3. Irrespective of glycerol source, biomass yield (g biomass/ g C consumed) was higher during the initial $24 \mathrm{~h}$ than later period of fermentation (24-96 h) (Fig 3). Higher biomass yield during the initial 24-32 h is due to abundance of nitrogen and other nutrients available in the medium for growth. Biomass yield was observed highest for pure glycerol indicating no growth inhibition or absence of inhibitory compounds in the medium. Biomass yield for BIOCARDEL, BIOLIQ and ROTHSAY were lower than pure glycerol due to growth inhibition. For BIOCARDEL, BIOLIQ and ROTHSAY, biomass yield was in the range of 0.800.98 during the initial $24 \mathrm{~h}$ and 0.60-0.70 during 24-96 h (Fig 3).

Lipid yield (Yl/s, g of lipid produced per g of C consumed) was observed highest for pure glycerol (for most of fermentation period) indicating no inhibitory compounds present in the medium (Figure 4a). Lowest citric yield in pure glycerol medium (Figure 4b) is another reason for highest lipid yield. For pure glycerol, a dip in biomass and lipid yield was observed during 24-48 h because of a shift in metabolism for growth phase to lipid production phase. ROTHSAY exhibited lowest lipid yield (0.15-0.05) because the majority of carbon source was used for citric acid production. Citric acid yield (0.32-2.2 g CA produced per g carbon consumed) for ROTHSAY 
(Figure 4b) was much higher than that lipid yield. For BIOLIQ glycerol, lipid yield was nearly constant throughout fermentation except between 16-32 h where there was a shift in metabolism from growth phase to citric acid production phase due to carbon feed (having high potassium concentration) added at $24 \mathrm{~h}$ (Figure 4b). For BIOCARDEL glycerol, lipid yield was comparatively higher during initial $24 \mathrm{~h}$ due to the formation of cell membrane lipids and after 72 $\mathrm{h}$, as $\mathrm{C} / \mathrm{N}$ ratio increased with feeding at $64 \mathrm{~h}$, which leads to lipid accumulation. A dip in lipid yield was observed during $24 \mathrm{~h}-72 \mathrm{~h}$ for BIOCARDEL because of the shift of metabolism from cell growth phase to lipid and citric acid production phase. A shift in metabolism occurred due to a reduction in nitrogen concentration in the medium. An increase in citric acid yield was also observed during 40-56 h (Figure 4b) due to increase in cellular activities and it doesn't follow denovo lipid accumulation.

Irrespective of glycerol source, citric acid yield was lower during initial $24 \mathrm{~h}$ and was higher during late stages of fermentation (24-96 h) (Figure 4b). Citric acid yield was higher during 24-96 $\mathrm{h}$ due to a decrease in nitrogen concentration and increase in the $\mathrm{C} / \mathrm{N}$ ratio in the medium. Citric acid yield was the highest for ROTHSAY, followed by BIOLIQ, BIOCARDEL and pure glycerol.

\subsubsection{Variation of specific growth rate}


For every glycerol source, the specific growth rate monotonically decreased until the end of the fermentation process (Figure 5). Such type of decreasing trend has also been reported in the literature ${ }^{21,30}$. For initial 24 h, specific growth rate was observed highest for pure glycerol (Figure 5a). Maximum specific growth rate $0.357,0.104,0.083$ and $0.092 \mathrm{~h}^{-1}$ for pure glycerol, BIOCARDEL, BIOLIQ and ROTHSAY glycerol, respectively was observed at $8 \mathrm{~h}$ (Figure 5a). This indicates that inhibition is present in BIOCARDEL, BIOLIQ and ROTHSAY as discussed in the above sections. During 40-96h, specific growth rate was the highest for BIOLIQ glycerol (Figure 5b).

\subsection{Impact of high concentration of elements on lipid and CA production}

Biomass concentration in pure glycerol medium was higher than all other pure glycerol medium with concentration of $\mathrm{Na}, \mathrm{K}$ and $\mathrm{S}$ (Fig 6a). At $96 \mathrm{~h}$, biomass concentration in pure glycerol medium, pure glycerol medium with high Na, pure glycerol medium with high $\mathrm{K}$ and pure glycerol medium with high S were $13.60 \mathrm{~g} / \mathrm{L}, 12.11 \mathrm{~g} / \mathrm{L}, 9.47 \mathrm{~g} / \mathrm{K}$ and $9.71 \mathrm{~g} / \mathrm{L}$, respectively. At 96 h, biomass concentration in pure glycerol medium with high Na, K and S was 11.0\%, 30.4\% and $28.6 \%$ lower than that of pure glycerol medium, respectively. It clearly indicates that high concentration of $\mathrm{Na}, \mathrm{K}$ and $\mathrm{S}$ in pure glycerol medium renders inhibition to cell growth of $Y$. lipolytica. 
Impact of high concentration of $\mathrm{Na}, \mathrm{K}$ and $\mathrm{S}$ in pure glycerol on lipid production is shown in Figure 6b. At 96 h, lipid concentration in pure glycerol medium, pure glycerol medium with high Na, pure glycerol medium with high $\mathrm{K}$ and pure glycerol medium with high S were 2.16 g/L, 1.57 $\mathrm{g} / \mathrm{L}, 1.38 \mathrm{~g} / \mathrm{L}$ and $1.12 \mathrm{~g} / \mathrm{L}$, respectively. Due to lower biomass in pure glycerol medium with high $\mathrm{Na}, \mathrm{K}$ and S, lower lipid concentration was obtained. At $96 \mathrm{~h}$, the biomass lipid content for pure glycerol, pure glycerol with high $\mathrm{Na}, \mathrm{K}$ and S were $15.9 \%, 12.9 \%, 11.8 \%$ and $14.2 \%$. Impact of high concentration of Na, K and S in pure glycerol on citric acid production is shown in Figure 6c. CA production in pure glycerol medium, pure glycerol with high $\mathrm{Na}, \mathrm{K}$ and $\mathrm{S}$ at $96 \mathrm{~h}$ were 0.00 $\mathrm{g} / \mathrm{L}, 0.79 \mathrm{~g} / \mathrm{L}, 1.47 \mathrm{~g} / \mathrm{L}, 1.86 \mathrm{~g} / \mathrm{L}$, respectively. This indicates that high concentration of $\mathrm{Na}, \mathrm{K}$ and S favours citric acid production while inhibiting biomass and lipid production by $Y$. lipolytica. Figure 6d indicates that glycerol consumption in pure glycerol medium, pure glycerol with high $\mathrm{Na}, \mathrm{K}$ and $\mathrm{S}$ at $96 \mathrm{~h}$ were $10.09 \mathrm{~g} / \mathrm{L}, 9.35 \mathrm{~g} / \mathrm{L}, 7.58 \mathrm{~g} / \mathrm{L}$ and $7.84 \mathrm{~g} / \mathrm{L}$, respectively.

\section{Discussion}

Growth inhibition was observed for Y. lipolytica SKY7 when high concentration of Na, K or $\mathrm{S}$ was present in the glycerol medium. A certain concentration of sodium in the medium is essential for cell growth and lipid production. However, it has been reported that high a sodium concentration in the medium presents a dual toxicity; ionic stress and hyperosmotic stress ${ }^{31}$. One factor contributing to ionic toxicity is the capacity of sodium to displace potassium or in some cases magnesium in the active sites of some enzymes, which leads to inhibition of cellular enzymes 
and activities ${ }^{31}$. A certain concentration of potassium in the media is certainly important for cellular activities because potassium is necessary for maintaining cell volume, enzyme activity, compensation of negative charges of macromolecules to electroneutrality, protein synthesis, maintenance of intracellular $\mathrm{pH}$ and membrane potential ${ }^{31}$. However, high extracellular potassium concentration is detrimental for cell growth and lipid production. High extracellular potassium concentration in the medium has reported to lead to hyperosmotic stress conditions leading to hamper the cellular activities required for the cell growth ${ }^{31}$. On the other hand, algal growth was reported to be inhibited on sparging $400 \mathrm{ppm}$ of $\mathrm{SO}_{2}$ in the medium, indicating that the $\mathrm{SO}_{2}$ concentration beyond a certain concentration inhibit the cell growth ${ }^{32}$.

Soap present in BIOCARDEL crude glycerol was converted to FFA before using it in the fermentation medium. This was done to minimize growth inhibition from high soap concentration. In a similar study reported in the literature, crude glycerol with high soap content was used for lipid production by $T$. oleaginosus ${ }^{17}$. It was found that a soap concentration of $36.5 \mathrm{~g} / \mathrm{L}$ in the medium proved inhibitory for cell growth of $T$. oleaginosus. Soap decreases motility of cells, impacts their orientation and transforms their morphology ${ }^{33,34}$. To resolve the problem of soap inhibition, batch fermentation was conducted using sterilized crude glycerol at $\mathrm{pH} 5$ where $98.71 \%$ soap was converted to FFA ${ }^{18}$. The fermentation was started with $23 \mathrm{~g} / \mathrm{L}$ FFA and $15 \mathrm{~g} / \mathrm{L}$ glycerol. It was observed that both FFA and glycerol were readily used by the microbial population during 
fermentation. This led to a high biomass $(0.44 \mathrm{~g} / \mathrm{L} / \mathrm{h})$ and lipid productivity $(0.22 \mathrm{~g} / \mathrm{L} / \mathrm{h})$ during the fermentation indicating no inhibition of $T$. oleaginosus from FFA ${ }^{18}$.

The lipid productivity in the BIOCARDEL glycerol medium (this study) was $0.154 \mathrm{~g} / \mathrm{L} / \mathrm{h}$. This is higher when compared with lipid productivity $(0.143 \mathrm{~g} / \mathrm{L} / \mathrm{h})$ obtained from genetically engineered $Y$. lipolytica grown on glucose medium in a batch fermentation ${ }^{35}$. It was also higher than that obtained by C. curvatus $(0.06 \mathrm{~g} / \mathrm{L} / \mathrm{h})$ and $L$. starkeyi $(0.13 \mathrm{~g} / \mathrm{L} / \mathrm{h})$ grown on crude glycerol

medium in a fed-batch mode ${ }^{16,36}$. This is due to faster assimilation of FFA present in BIOCARDEL along with glycerol. As discussed in section 3.2.3, hydrophobic substrate like FFA follow ex novo lipid accumulation process and is independent of nitrogen concentration in the medium.

Lipid was produced by Yarrowia lipolytica using crude glycerol procured from different industries in another study ${ }^{37}$. Crude glycerol obtained from soap company was high on glycerol and fatty acids, whereas crude glycerol obtained from stearin (tri-glyceride of stearic acid) manufacturing company was high on glycerol and water content. A very long lag phase (24-30 h) was observed for crude glycerol obtained from stearin production industries. However, when the crude glycerol from soap industry was used, the cell growth was higher than other crude glycerol samples. This was due to the fact that during the saponification process in the soap industry, plant 
or animal fat is hydrolyzed leading to the residues of fatty esters, which were easily utilized by $Y$. lipolytica (as compared to glycerol alone) resulting in higher biomass and lipid production. The crude glycerol obtained from soap industry obtained $1.69 \mathrm{~g} / \mathrm{L}$ lipid concentration (25.0\% w/w) with a biomass yield of $0.17 \mathrm{~g} / \mathrm{g}$ in shake flasks. Further, the lipid concentration of $4.72 \mathrm{~g} / \mathrm{L}$ was obtained with a biomass yield of $0.21 \mathrm{~g} / \mathrm{g}$ in a bioreactor.

Methanol in the growth medium can impact cell growth and lipid production. In this study, methanol present in BIOCARDEL evaporated during sterilization. In one of the studies, the effect of methanol in $50 \mathrm{~g} / \mathrm{L}$ pure glycerol was investigated on lipid production by $R$. toruloides ${ }^{38}$. It was found that adding $4 \mathrm{~g} / \mathrm{L}$ methanol in pure glycerol decreased biomass concentration from $17.7 \mathrm{~g} / \mathrm{L}$ to $16.7 \mathrm{~g} / \mathrm{L}$ and lipid concentration from $6.2 \mathrm{~g} / \mathrm{L}$ to $5.7 \mathrm{~g} / \mathrm{L}$. Inhibition of growth due to presence of methanol in the medium can be due to alteration of membrane fluidity.

In another study, effect of methanol present in the crude glycerol was investigated on lipid production using $T$. oleaginosus ${ }^{15}$. Non-sterilized crude glycerol was used as carbon source with different methanol concentration: $1.4 \%(\mathrm{w} / \mathrm{v}), 2.2 \%(\mathrm{w} / \mathrm{v}), 3.3 \%(\mathrm{w} / \mathrm{v})$ and $4.4 \%(\mathrm{w} / \mathrm{v})$. It was found that a lipid concentration of $3.29 \mathrm{~g} / \mathrm{L}$ was obtained at $42 \mathrm{~h}$ with $1.4 \%(\mathrm{w} / \mathrm{v})$ methanol in batch fermentation. Increase in methanol concentration decreased the biomass and lipid concentration due to the toxic effects of methanol on cell growth and lipid accumulation. However, 
when fermentation was conducted in a fed-batch mode with non-sterilized crude glycerol (with $1.4 \% \mathrm{w} / \mathrm{v}$ methanol), high biomass (43.22 g/L) and lipid concentration (20.78 g/L) was observed at $60 \mathrm{~h}$. Such a process may not be feasible in industrial practice as colonies other than $T$. oleaginosus were also growing in the medium and the concentration of these colonies may vary from batch to batch.

The citric acid productivity for Y. lipolytica SKY7 in ROTHSAY glycerol (this study) was $0.195 \mathrm{~g} / \mathrm{L} / \mathrm{h}$, which is lower than productivity $(0.46 \mathrm{~g} / \mathrm{L} / \mathrm{h})$ of genetically engineered strain of $Y$. lipolytica grown on glucose ${ }^{39}$. High citric acid production in genetically modified strain was due to cloning and over-expression of pyruvate carboxylase gene, PYC1 gene (obtained from marine fungus) in citric acid producing wild strain of Y. lipolytica SWJ- $1 \mathrm{~b}^{39}$. In Y. lipolytica SWJ- 1b, pyruvate carboxylase catalyzes the carboxylation of one mole of pyruvic acid to oxaloacetic acid by fixing $1 \mathrm{~mol}$ of $\mathrm{CO}_{2}$. The oxaloacetic acid formed is reduced to malate, and the malate enters into mitochondria where the malate is oxidized to oxaloacetic acid. At the same time, another mole of pyruvic acid is converted into acetyl-CoA under the catalysis of mitochondrion pyruvate dehydrogenase (mPDH) by releasing $1 \mathrm{~mol}$ of $\mathrm{CO}_{2}$ in the mitochondria. Then, oxaloacetic acid and acetyl-CoA are condensed to form CA in mitochondria.

Therefore, due to overexpression of pyruvate carboxylase, more oxaloacetic acid exists in the mitochondria and hence higher CA is formed. Another reason for lower CA productivity in ROTHSAY glycerol medium (this study) is that with glycerol as the sole carbon source, only $6.7 \%$ 
of its uptake rate is directed to phosphate pentose pathway (PPP) compared to 35\% with glucose

${ }^{40}$. On the other hand, higher fluxes toward the tri-carboxylic acid (TCA) cycle are observed with glycerol rather than glucose as substrate. The relatively lower TCA cycle and higher PPP fluxes could explain the higher citrate produced with glucose as the sole carbon source.

Moreover, the higher PPP fluxes would also reduce the fluxes toward the NADP dependent isocitrate dehydrogenase, reported to be present in $Y$. lipolytica, the major citrate degrading enzyme. However, crude glycerol $(0.1-0.15 \$ / \mathrm{kg})$ is an inexpensive substrate when compared to glucose $(\$ 1 / \mathrm{kg})$.

Citric acid productivity for Y. lipolytica SKY7 in ROTHSAY glycerol (0.195 g/L/h) was higher than reported on same strain cultivated on different type of crude glycerol $(0.093 \mathrm{~g} / \mathrm{L} / \mathrm{h})^{21}$. The crude glycerol used in the reported study had following (w/v) composition: 78.0\% glycerol, $1.3 \%$ methanol, $2.4 \%$ soap, $0.1 \%$ catalyst $0.1 \%$, and $2.5 \%$ water ${ }^{21}$. High CA productivity in this study was due to high concentration of sulphur in crude glycerol medium favoring CA production.

\section{Conclusion}

Growth inhibition was observed in BIOCARDEL, BIOLIQ and ROTHSAY glycerol when compared with pure glycerol. This was due to high sodium concentration in BIOCARDEL, high potassium concentration in BIOLIQ and high sulphur concentration in ROTHSAY glycerol. 
Among three crude glycerol sources, the highest biomass and lipid concentrations were obtained in BIOCARDEL crude glycerol while the lowest biomass and lipid concentrations were obtained in ROTHSAY glycerol. However, higher potassium and sulphur concentrations in BIOLIQ and ROTHSAY, respectively led to high citric acid production (12.00 g/L and $18.70 \mathrm{~g} / \mathrm{L})$.

Acknowledgements: The authors would like to acknowledge the Natural Sciences and Engineering Research Council of Canada (grant A4984, Canada Research Chair) for financial support. We are grateful to the technical staffs of INRS-ETE (Mr. Stephane Moise and Mr. Stefane Premont) for their timely help to analyze the samples on LC-MS and ICP-MS. The authors acknowledge different biodiesel producing companies of Canada for providing the crude glycerol for the research work. 


\section{References}

1. Vyas AP, Verma JL and Subrahmanyam N, A review on FAME production processes. Fuel 89: 19 (2010).

2. Mathiazhakan K, Ayed D and Tyagi RD, Kinetics of lipid production at lab scale fermenters by a new isolate of Yarrowia lipolytica SKY7. Bioresource Technology 221: 234-240 (2016).

3. Chen H-H, Xue L-L, Liang M-H and Jiang J-G, Effects of triethylamine on the expression patterns of two G3PDHs and lipid accumulation in Dunaliella tertiolecta. Enzyme and microbial technology 127: 17-21 (2019).

4. Chen H-H, Xue L-L, Liang M-H and Jiang J-G, Sodium azide intervention, salinity stress and twostep cultivation of Dunaliella tertiolecta for lipid accumulation. Enzyme and microbial technology 127: 1-5 (2019).

5. Wang Y, Gong Z, Yang X, Shen H, Wang Q, Wang J and Zhao ZK, Microbial lipid production from pectin-derived carbohydrates by oleaginous yeasts. Process Biochemistry 50: 1097-1102 (2015).

6. Zhang X, Chen J, Yan S, Tyagi RD, Surampalli RY and Li J, Lipid Production for Biodiesel from Sludge and Crude Glycerol. Water Environment Research 89: 424-439 (2017).

7. Kumar LR, Yellapu SK, Zhang X and Tyagi RD, Energy balance for biodiesel production processes using microbial oil and scum. Bioresource technology 272: 379-388 (2019).

8. Kumar LR, Kaur R, Yellapu SK, Zhang X and Tyagi RD, Chapter 27 - Biodiesel Production From Oleaginous Microorganisms With Wastes as Raw Materials, in Biofuels: Alternative Feedstocks and Conversion Processes for the Production of Liquid and Gaseous Biofuels (Second Edition), ed by Pandey A, Larroche C, Dussap C-G, Gnansounou E, Khanal SK and Ricke S. Academic Press, pp. 661-690 (2019).

9. Zhang X, Chen J, Idossou V, Tyagi RD, Li J and Wang H, Lipid accumulation from Trichosporon oleaginosus with co-fermentation of washed wastewater sludge and crude glycerol. Fuel 226: 93102 (2018).

10. Zhang X, Yan S, Tyagi RD, Surampalli RY and Valéro JR, Energy balance of biofuel production from biological conversion of crude glycerol. Journal of environmental management 170: 169-176 (2016).

11. Zhang X, Chen J, Wu D, Li J, Tyagi RD and Surampalli RY, Economical lipid production from Trichosporon oleaginosus via dissolved oxygen adjustment and crude glycerol addition. Bioresource technology 273: 288-296 (2019).

12. Adewale P, Dumont M-J and Ngadi M, Recent trends of biodiesel production from animal fat wastes and associated production techniques. Renewable and Sustainable Energy Reviews 45: 574588 (2015).

13. Veljković VB, Banković-Ilić IB and Stamenković OS, Purification of crude biodiesel obtained by heterogeneously-catalyzed transesterification. Renewable and Sustainable Energy Reviews 49: 500-516 (2015).

14. Gao Z, Ma Y, Wang Q, Zhang M, Wang J and Liu Y, Effect of crude glycerol impurities on lipid preparation by Rhodosporidium toruloides yeast 32489. Bioresource technology 218: 373-379 (2016). 
15. Chen J, Zhang X, Tyagi RD and Drogui P, Utilization of methanol in crude glycerol to assist lipid production in non-sterilized fermentation from Trichosporon oleaginosus. Bioresource Technology 253: 8-15 (2018).

16. Liang Y, Sarkany N, Cui Y and Blackburn JW, Batch stage study of lipid production from crude glycerol derived from yellow grease or animal fats through microalgal fermentation. Bioresource technology 101: 6745-6750 (2010).

17. Chen J, Zhang X, Drogui $\mathrm{P}$ and Tyagi RD, The $\mathrm{pH}$-based fed-batch for lipid production from Trichosporon oleaginosus with crude glycerol. Bioresource technology 259: 237-243 (2018).

18. Chen J, Zhang X, Yan S, Tyagi RD and Drogui P, Lipid production from fed-batch fermentation of crude glycerol directed by the kinetic study of batch fermentations. Fuel 209: 1-9 (2017).

19. Kuttiraja M, Krishna S, Dhouha A and Tyagi RD, A substrate-based approach for the selection of oil-bearing heterotrophs from nitrogen-deficient soil for lipid production. Applied biochemistry and biotechnology 175: 1926-1937 (2015).

20. Yen H-W and Zhang Z, Effects of dissolved oxygen level on cell growth and total lipid accumulation in the cultivation of Rhodotorula glutinis. Journal of bioscience and bioengineering 112: $71-74$ (2011).

21. Kuttiraja M, Dhouha A and Tyagi RD, Harnessing the Effect of pH on Lipid Production in Batch Cultures of Yarrowia lipolytica SKY7. Applied Biochemistry and Biotechnology 184: 1332-1346 (2018).

22. Ykema A, Verbree EC, Kater MM and Smit H, Optimization of lipid production in the oleaginous yeastApiotrichum curvatum in wheypermeate. Applied microbiology and biotechnology 29: 211218 (1988).

23. Bondioli P and Della Bella L, An alternative spectrophotometric method for the determination of free glycerol in biodiesel. European journal of lipid science and technology 107: 153-157 (2005).

24. Beopoulos A, Chardot T and Nicaud J-M, Yarrowia lipolytica: A model and a tool to understand the mechanisms implicated in lipid accumulation. Biochimie 91: 692-696 (2009).

25. Carsanba E, Papanikolaou S and Erten H, Production of oils and fats by oleaginous microorganisms with an emphasis given to the potential of the nonconventional yeast Yarrowia lipolytica. Critical reviews in biotechnology 38: 1230-1243 (2018).

26. Papanikolaou S, Beopoulos A, Koletti A, Thevenieau F, Koutinas AA, Nicaud J-M and Aggelis G, Importance of the methyl-citrate cycle on glycerol metabolism in the yeast Yarrowia lipolytica. Journal of biotechnology 168: 303-314 (2013).

27. EVANS CT, SCRAGG AH and RATLEDGE C, A comparative study of citrate efflux from mitochondria of oleaginous and non-oleaginous yeasts. The FEBS Journal 130: 195-204 (1983).

28. Soccol CR, Vandenberghe LP, Rodrigues C and Pandey A, New perspectives for citric acid production and application. Food Technology \& Biotechnology 44: 141-149 (2006).

29. Vuoristo KS, Mars AE, Sanders JP, Eggink G and Weusthuis RA, Metabolic engineering of TCA cycle for production of chemicals. Trends in biotechnology 34: 191-197 (2016).

30. Kuttiraja M, Douha A, Valéro JR and Tyagi RD, Elucidating the Effect of Glycerol Concentration and C/N Ratio on Lipid Production Using Yarrowia lipolytica SKY7. Applied biochemistry and biotechnology 180: 1586-1600 (2016).

31. Yenush L, Potassium and Sodium Transport in Yeast, pp. 187-228 (2016).

32. Negoro M, Shioji N, Miyamoto K and Micira Y, Growth of Microalgae in High $\mathrm{CO}_{2}$ Gas and Effects of $\mathrm{SO}_{\mathrm{x}}$ and $\mathrm{NO}_{\mathrm{x}}$. Applied Biochemistry and Biotechnology 28: 877 (1991). 
33. Kosmela P, Kazimierski P, Formela K, Haponiuk J and Piszczyk Ł, Liquefaction of macroalgae Enteromorpha biomass for the preparation of biopolyols by using crude glycerol. Journal of Industrial and Engineering Chemistry 56: 399-406 (2017).

34. Rahman MS, Xu CC and Qin W, Biotransformation of biodiesel-derived crude glycerol using newly isolated bacteria from environmental consortia. Process Biochemistry 63: 177-184 (2017).

35. Tai M and Stephanopoulos G, Engineering the push and pull of lipid biosynthesis in oleaginous yeast Yarrowia lipolytica for biofuel production. Metabolic engineering 15: 1-9 (2013).

36. Signori L, Ami D, Posteri R, Giuzzi A, Mereghetti P, Porro D and Branduardi P, Assessing an effective feeding strategy to optimize crude glycerol utilization as sustainable carbon source for lipid accumulation in oleaginous yeasts. Microbial cell factories 15: 75 (2016).

37. Dobrowolski A, Mituła P, Rymowicz W and Mirończuk AM, Efficient conversion of crude glycerol from various industrial wastes into single cell oil by yeast Yarrowia lipolytica. Bioresource technology 207: 237-243 (2016).

38. Yang X, Jin G, Gong Z, Shen H, Bai F and Zhao ZK, Recycling biodiesel-derived glycerol by the oleaginous yeast Rhodosporidium toruloides Y4 through the two-stage lipid production process. Biochemical engineering journal 91: 86-91 (2014).

39. Fu G-Y, Lu Y, Chi Z, Liu G-L, Zhao S-F, Jiang H and Chi Z-M, Cloning and characterization of a pyruvate carboxylase gene from Penicillium rubens and overexpression of the genein the yeast Yarrowia lipolytica for enhanced citric acid production. Marine biotechnology 18: 1-14 (2016).

40. Sabra W, Bommareddy RR, Maheshwari G, Papanikolaou S and Zeng A-P, Substrates and oxygen dependent citric acid production by Yarrowia lipolytica: insights through transcriptome and fluxome analyses. Microbial cell factories 16: 78 (2017). 


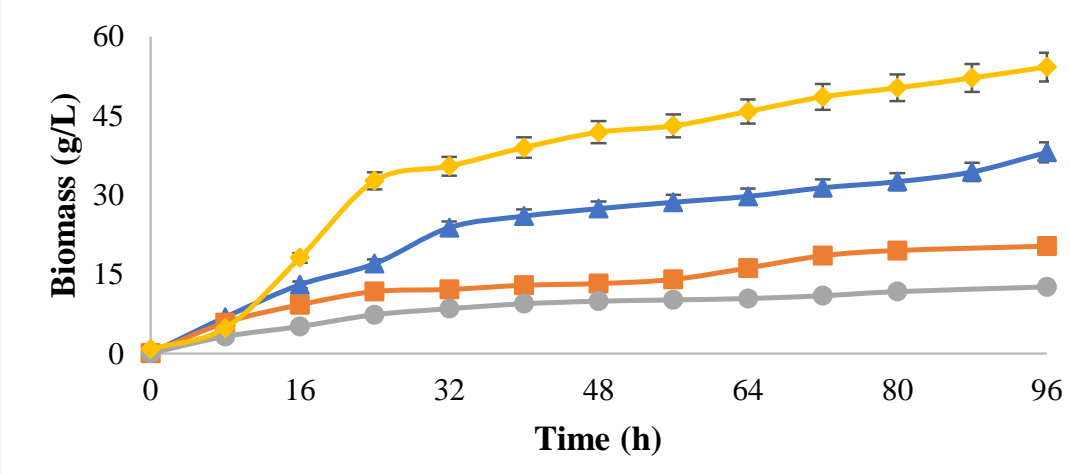

$\multimap$ BIOCARDEL $\multimap$ BIOLIQ - ROTHSAY $\multimap$ Pure glycerol

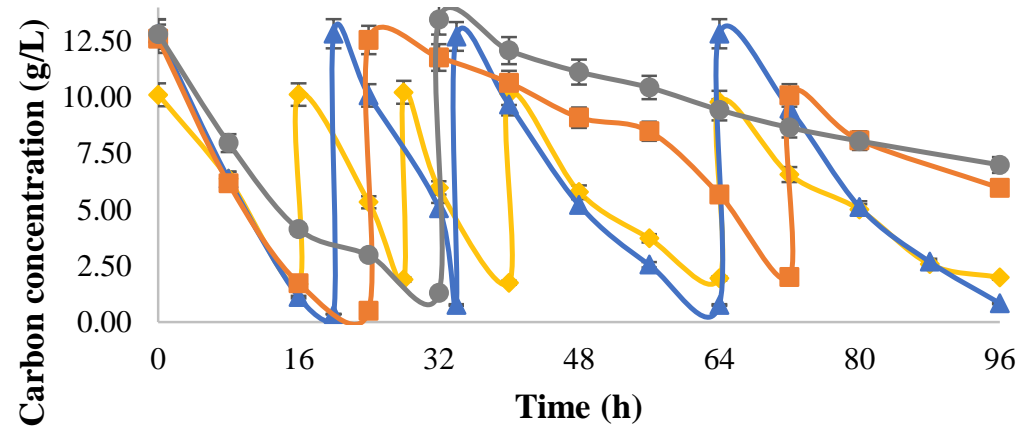

$\multimap$ Pure glycerol $\multimap$ BIOCARDEL $\multimap$ BIOLIQ $\multimap$ ROTHSAY

a)

b)

This article is protected by copyright. All rights reserved. 


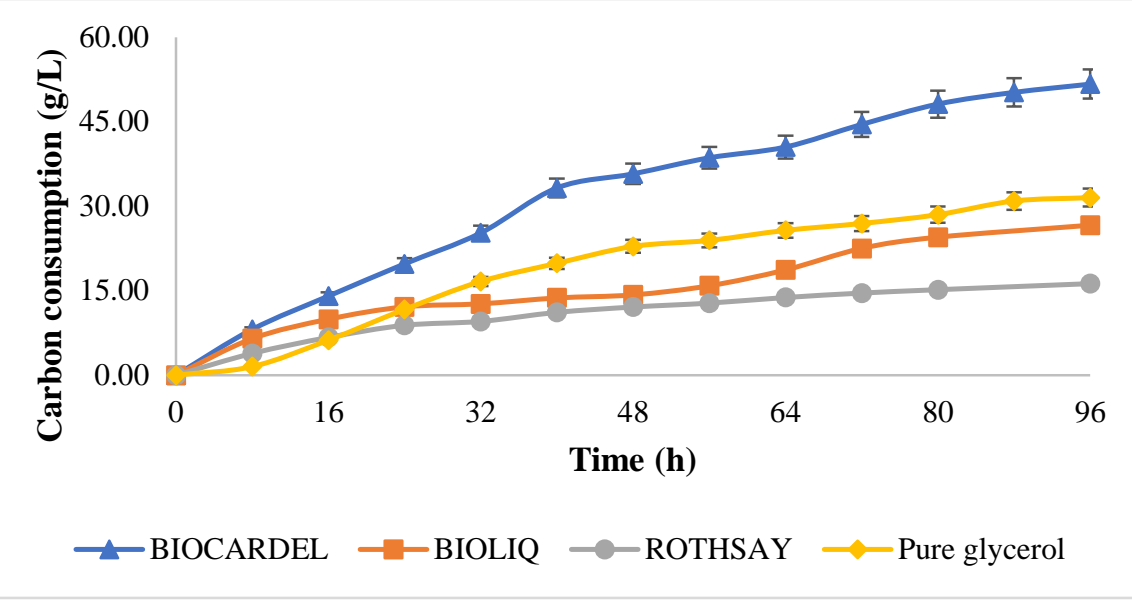

c)

Figure 1: a) Biomass concentration profile for different glycerol sources b) Carbon concentration profile in the fermenter and c) Carbon consumption profile for different glycerol sources (fed batch fermentation) 


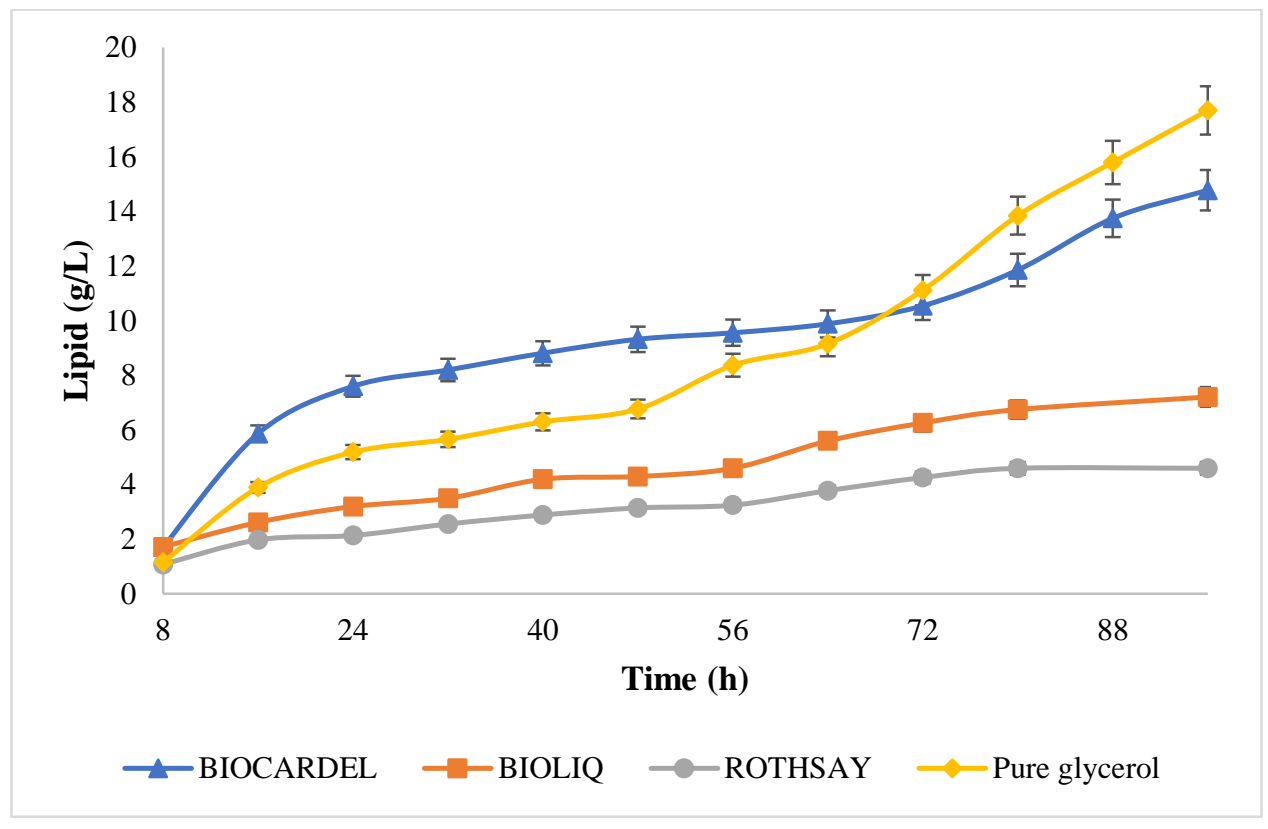

a)

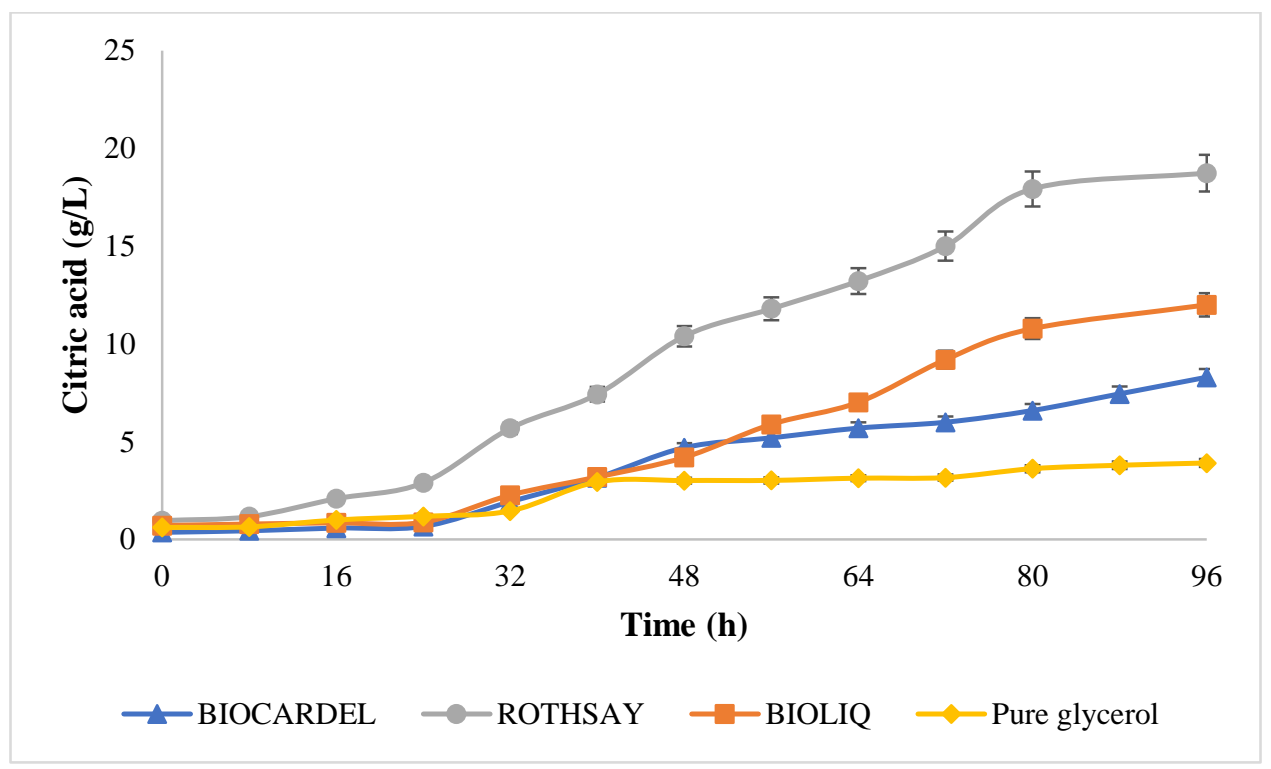

b)

Figure 2: a) Lipid concentration profile and b) Citric acid concentration profile for different glycerol sources (fed batch fermentation) 


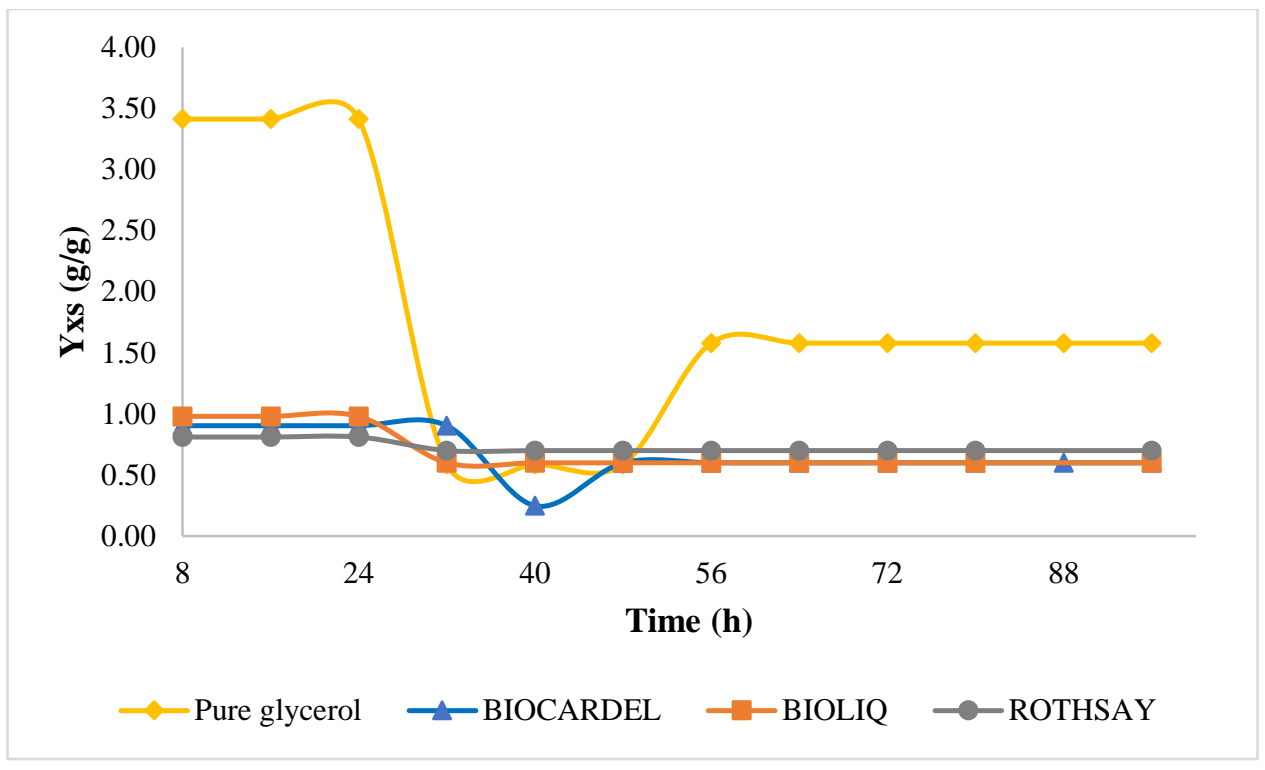

Figure 3: Biomass yield (g/g carbon) for different glycerol sources (fed batch fermentation) 


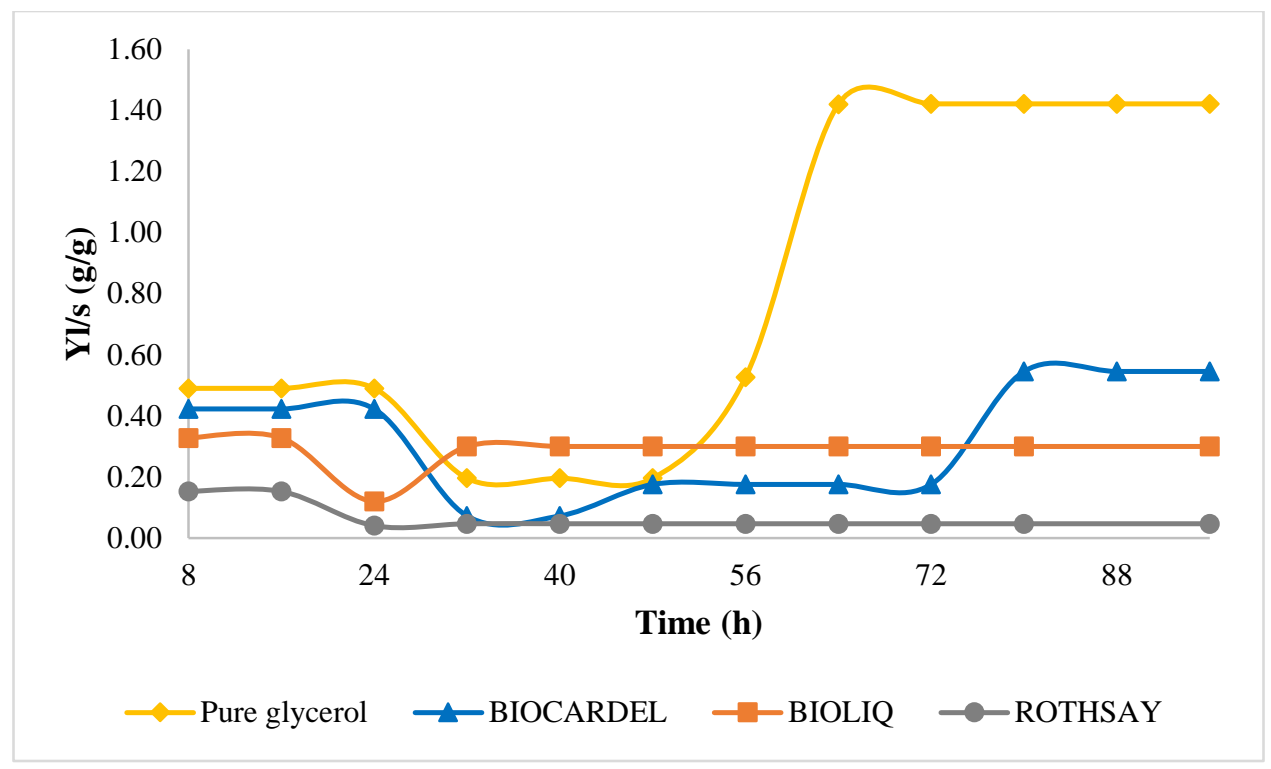

a)

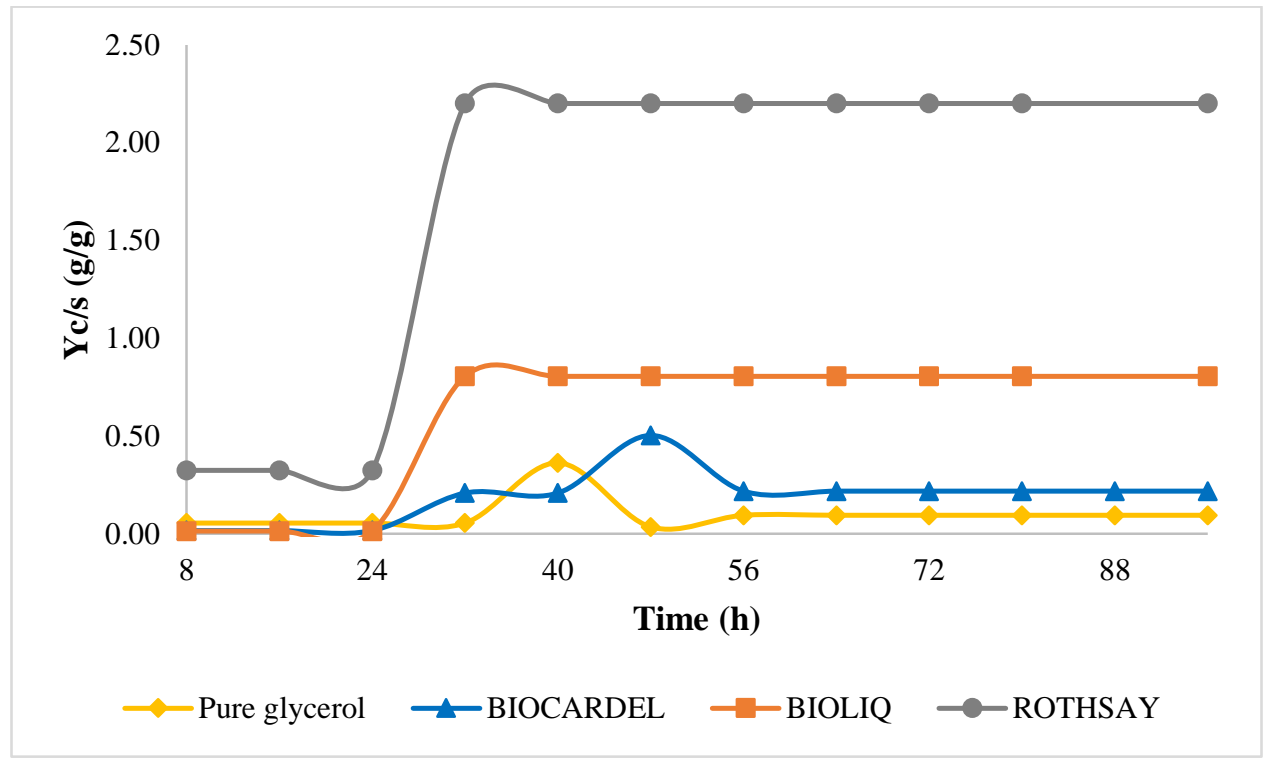

b)

Figure 4: a) Lipid yield (g/g carbon) and b) Citric acid yield (g/g carbon) for different glycerol sources (fed batch fermentation) 


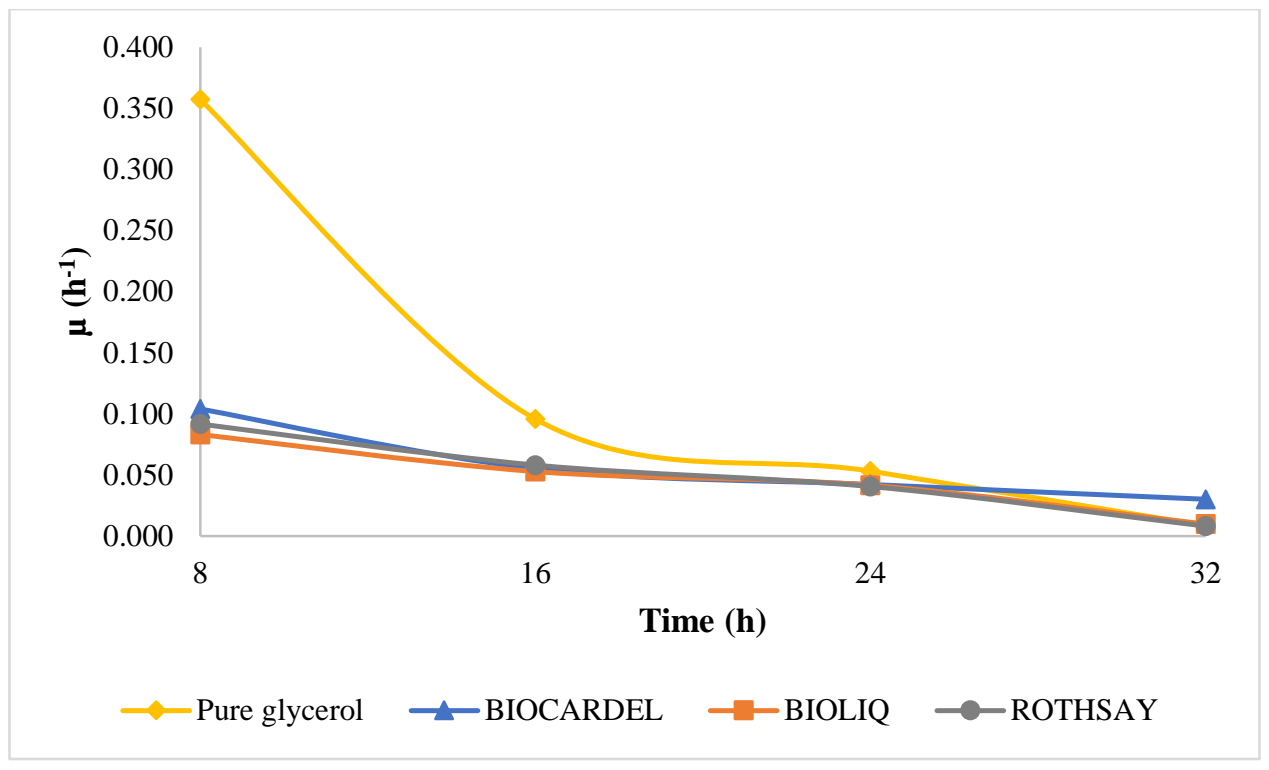

a)

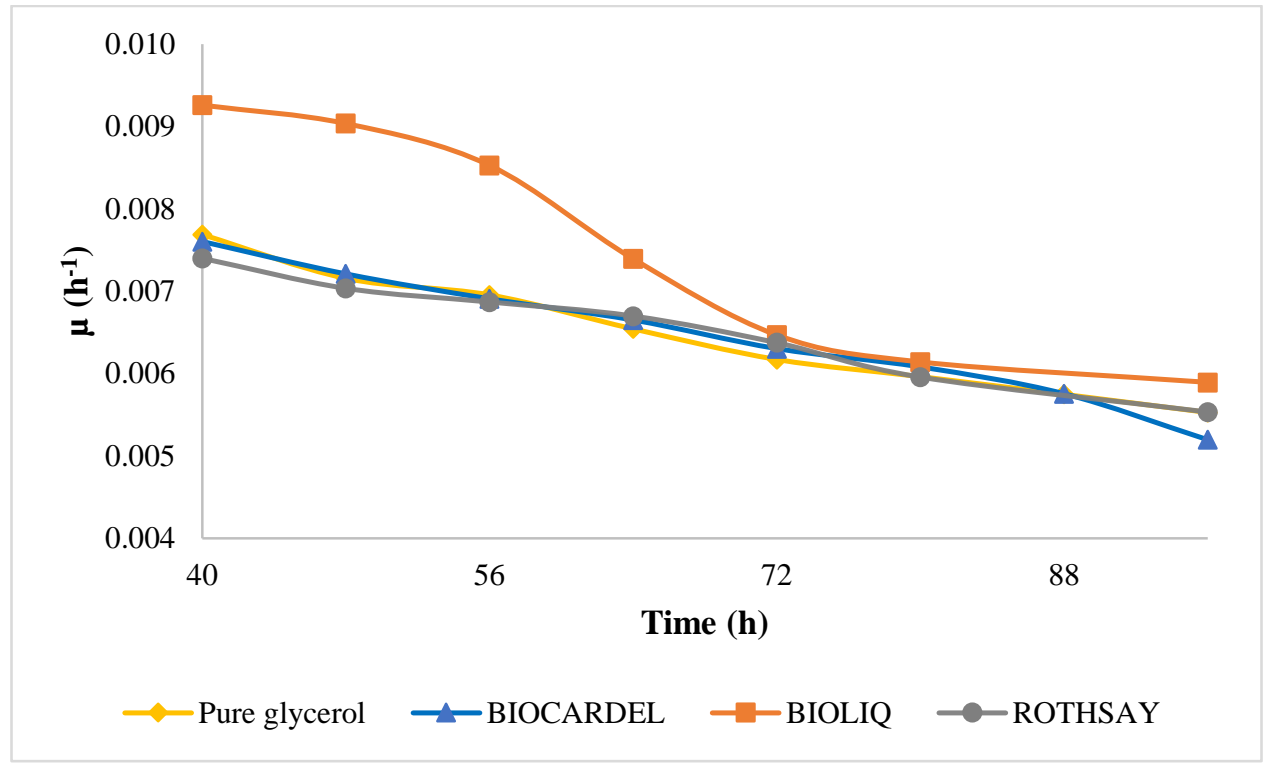

b)

Figure 5: Specific growth rate during a) initial $32 \mathrm{~h}$ and b) 40-96 h for different glycerol sources (fed batch fermentation) 


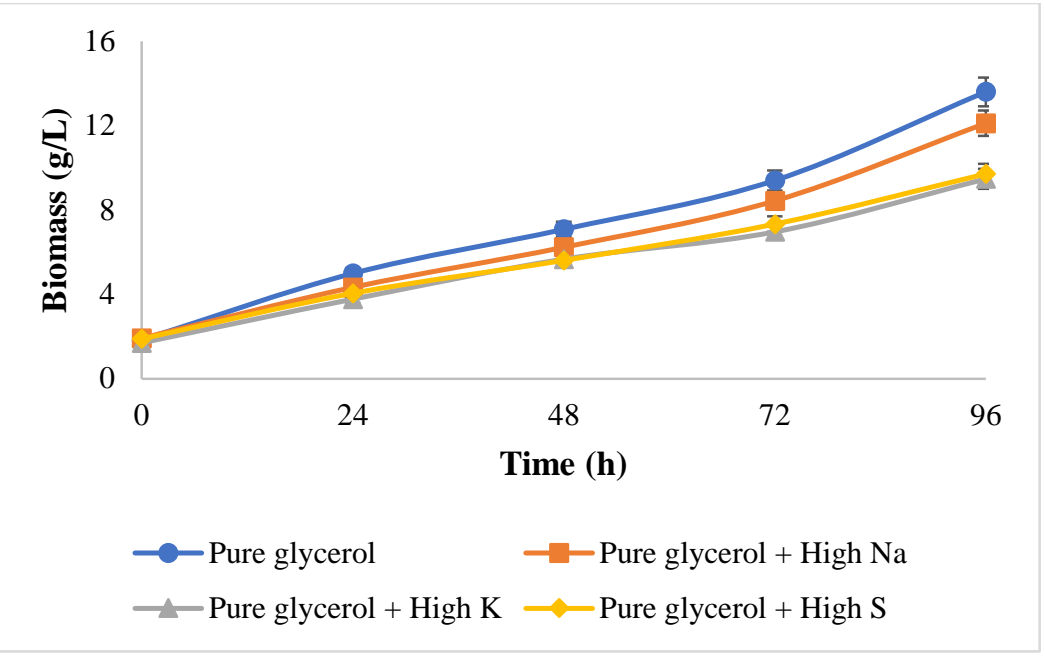

a)

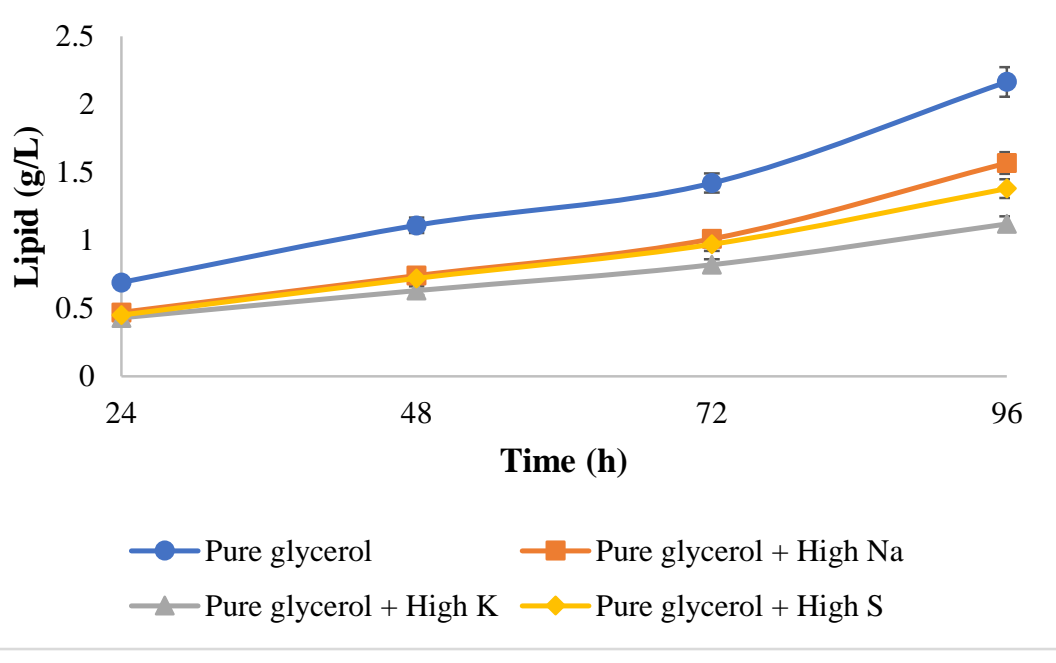

b)

This article is protected by copyright. All rights reserved. 


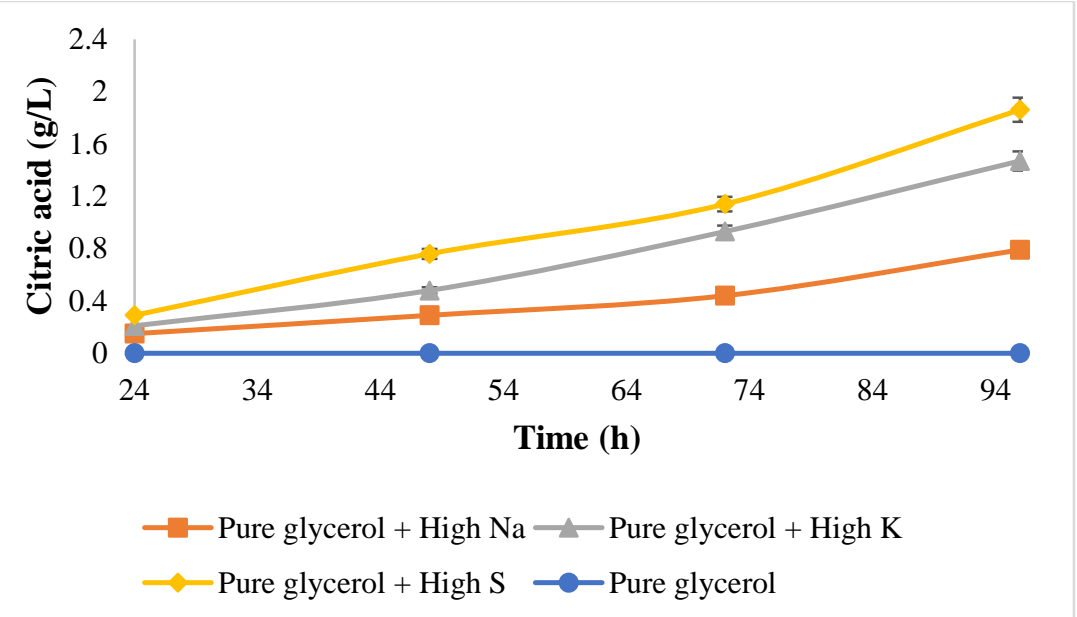

c)

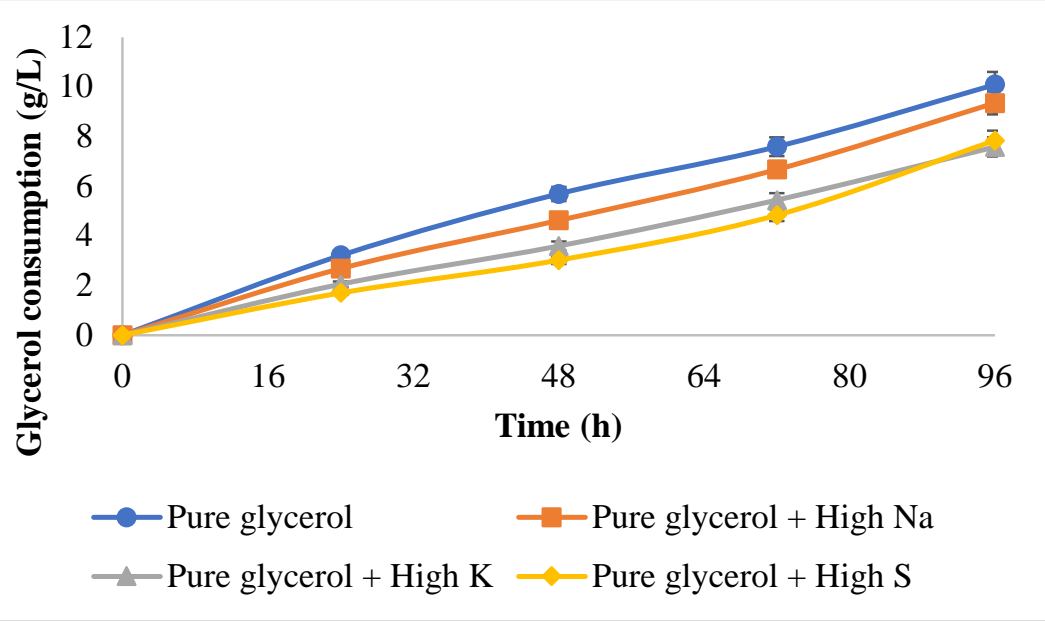

d)

Figure 6: Impact of high concentration of $\mathrm{Na}, \mathrm{K}$ and $\mathrm{S}$ in pure glycerol on a) Biomass concentration b) Lipid concentration c) Citric acid production and d) Glycerol consumption (shake-flask study) 
Table 1: Characterization of crude glycerol from three different biodiesel producing companies

\begin{tabular}{|c|c|c|c|}
\hline Parameter & BIOCARDEL & BIOLIQ & ROTHSAY \\
\hline Density (g/L) & 877.00 & 1300.00 & 1266.00 \\
\hline Glycerol concentration (g/L) & 120.00 & 650.00 & 504.00 \\
\hline Soap (g/L) & 263.10 & 0.00 & 00 \\
\hline Water $(\mathrm{g} / \mathrm{L})$ & 219.25 & 234.00 & 278.50 \\
\hline Methanol (g/L) & 263.10 & 0.00 & 0.00 \\
\hline $\mathrm{pH}$ & 9.0 & 14.0 & 2.5 \\
\hline $\mathrm{Al}(\mathrm{mg} / \mathrm{L})$ & 1.94 & 6.37 & 42.54 \\
\hline B (mg/ L) & 0.37 & 3.64 & 532.00 \\
\hline $\mathrm{Ca}(\mathrm{mg} / \mathrm{L})$ & 77.18 & 35.00 & 15.32 \\
\hline Co $(\mu \mathrm{g} / \mathrm{L})$ & - & - & 219.00 \\
\hline $\mathrm{Cr}(\mathrm{mg} / \mathrm{L})$ & 1.40 & 0.14 & 7.2 \\
\hline $\mathrm{Cu}(\mathrm{mg} / \mathrm{L})$ & 3.03 & 10.00 & 0.08 \\
\hline $\mathrm{Fe}(\mathrm{mg} / \mathrm{L})$ & 199.00 & 12.20 & 91.16 \\
\hline $\mathrm{K}(\mathrm{g} / \mathrm{L})$ & 0.20 & 70.84 & 0.23 \\
\hline $\mathrm{Mg}(\mathrm{mg} / \mathrm{L})$ & 52.62 & 17.80 & 7.90 \\
\hline Mn (mg/ L) & 1.64 & 0.20 & 0.45 \\
\hline Mo $(\mu \mathrm{g} / \mathrm{L})$ & 87.70 & - & 4520.00 \\
\hline $\mathrm{Na}(\mathrm{g} / \mathrm{L})$ & 12.80 & 6.60 & 9.00 \\
\hline $\mathrm{Ni}(\mathrm{mg} / \mathrm{L})$ & 0.26 & 0.13 & 30.13 \\
\hline$P(g / L)$ & 0.39 & 0.13 & 0.70 \\
\hline $\mathrm{S}(\mathrm{g} / \mathrm{L})$ & 3.20 & 0.15 & 11.00 \\
\hline Si (mg/ L) & 12.54 & 35.00 & 30.13 \\
\hline Sn (mg/L) & 350.00 & 39.00 & 379.80 \\
\hline $\operatorname{Sr}(\mu \mathrm{g} / \mathrm{L})$ & 438.50 & - & - \\
\hline $\mathrm{Ti}(\mu \mathrm{g} / \mathrm{L})$ & 87.70 & - & - \\
\hline $\mathrm{Zn}(\mathrm{mg} / \mathrm{L})$ & 12.72 & 1.80 & 1.80 \\
\hline
\end{tabular}


Table 2(a): Feeding details for different glycerol sources during fed-batch culture.

\begin{tabular}{|c|c|c|c|c|c|c|c|c|c|c|c|c|c|c|}
\hline \multirow{2}{*}{$\begin{array}{c}\begin{array}{c}\text { Feeding time and } \\
\text { component }\end{array} \\
\text { Time (h) }\end{array}$} & \multicolumn{5}{|c|}{ Pure glycerol } & \multicolumn{4}{|c|}{ BIOCARDEL } & \multicolumn{3}{|c|}{ BIOLIQ } & \multicolumn{2}{|c|}{ ROTHSAY } \\
\hline & $\mathbf{0}$ & 16 & 28 & 45 & 64 & $\mathbf{0}$ & 20 & 34 & 64 & $\mathbf{0}$ & 24 & 72 & $\mathbf{0}$ & 32 \\
\hline $\begin{array}{l}\text { Glycerol added } \\
\text { (g/L) }\end{array}$ & 25 & 21 & 21 & 21 & 21 & 6 & 6 & 6 & 6 & 33 & 33 & 21 & 33 & 31 \\
\hline FFA added (g/L) & 0 & 0 & 0 & 0 & 0 & 15.2 & 15.2 & 15.2 & 15.2 & 0 & 0 & 0 & 0 & 0 \\
\hline $\begin{array}{c}\text { Total Carbon } \\
\text { added (g/L) }\end{array}$ & 10 & 8.2 & 8.2 & 8.2 & 8.2 & 13 & 13 & 13 & 13 & 13 & 13 & 8.2 & 13 & 12 \\
\hline $\begin{array}{c}\text { Nitrogen added } \\
(\mathrm{g} / \mathrm{L})\end{array}$ & 1.13 & - & - & - & - & 1.5 & - & - & - & 1.49 & - & - & 1.5 & - \\
\hline
\end{tabular}

Table 2(b): Elemental concentration and molar $\mathrm{C} / \mathrm{N}$ ratio in fermenter media for different glycerol sources

\begin{tabular}{|c|c|c|c|c|c|c|c|c|c|c|c|c|c|c|}
\hline \multirow{2}{*}{ Elements } & \multicolumn{5}{|c|}{ Pure glycerol } & \multicolumn{4}{|c|}{ BIOCARDEL } & \multicolumn{3}{|c|}{ BIOLIQ } & \multicolumn{2}{|c|}{ ROTHSAY } \\
\hline & $\mathbf{O h}$ & $16 \mathrm{~h}$ & $28 \mathrm{~h}$ & $45 \mathrm{~h}$ & $64 \mathrm{~h}$ & $\mathbf{O h}$ & $20 \mathrm{~h}$ & $34 \mathrm{~h}$ & $64 \mathrm{~h}$ & $\mathbf{O} \mathbf{h}$ & $24 \mathrm{~h}$ & $72 \mathrm{~h}$ & $\mathbf{O} \mathbf{h}$ & $32 \mathrm{~h}$ \\
\hline$K(g / L)$ & 1.43 & 1.46 & 1.22 & 1.24 & 1.13 & 1.3 & 1.18 & 1.24 & 1.26 & 4.8 & 6.32 & 8.42 & 1.53 & 1.2 \\
\hline $\mathrm{Na}(\mathrm{g} / \mathrm{L})$ & 0.70 & 1.64 & 1.92 & 2.3 & 3.72 & 1.99 & 2.18 & 6 & 8.3 & 0.96 & 1.7 & 3.67 & 5.3 & 7.4 \\
\hline$P(g / L)$ & 0.99 & 0.88 & 0.68 & 0.66 & 0.58 & 0.9 & 0.79 & 0.84 & 0.86 & 0.98 & 0.87 & 0.7 & 0.9 & 0.7 \\
\hline$S(g / L)$ & 0.3 & 0.5 & 0.5 & 0.6 & 1.24 & 1.39 & 1.3 & 2.4 & 3.14 & 2 & 2.6 & 3.7 & 3.92 & 4.02 \\
\hline $\mathrm{C} / \mathrm{N}$ & 10.32 & 13.41 & 32.41 & 38.89 & 46.21 & 10.18 & 17.64 & 35.96 & 48.94 & 10.18 & 24.7 & 45.50 & 10.14 & 35.91 \\
\hline
\end{tabular}


Table 3: Lipid profile of Y. lipolytica SKY7 at end of fermentation in different glycerol sources

\begin{tabular}{ccccc}
\hline Fatty acid & Pure glycerol & BIOCARDEL & BIOLIQ & ROTHSAY \\
\hline C14:0 (Mysteric acid) & $20.77 \%$ & - & $7.73 \%$ & $14.90 \%$ \\
C15:1 & - & - & $7.75 \%$ & $9.24 \%$ \\
C16:0 (Palmitic acid) & $21.35 \%$ & $18.82 \%$ & $6.14 \%$ & $15.70 \%$ \\
C16:2 & - & - & $5.76 \%$ & $9.16 \%$ \\
C18:0 (Stearic acid) & - & $8.53 \%$ & $4.39 \%$ & $5.66 \%$ \\
C18:1 (Oleic acid) & $27.09 \%$ & $47.65 \%$ & $11.50 \%$ & $14.74 \%$ \\
C18:2 (Linoleic acid) & $16.73 \%$ & $9.05 \%$ & $42.05 \%$ & $22.40 \%$ \\
C18:3 (Linolenic acid) & $3.84 \%$ & - & - & - \\
C18:4 (Stearidonic acid) & - & $1.83 \%$ & - & - \\
C20:0 (Arachidic acid) & $3.60 \%$ & - & - & $8.20 \%$ \\
C20:1 (Eicosenoate) & - & $14.11 \%$ & $11.19 \%$ & - \\
C20:4 (Arachidonic acid) & $6.62 \%$ & - & $3.48 \%$ & - \\
\hline
\end{tabular}


Table 4: Organic acids produced by Y. lipolytica SKY7 at end of fermentation using different glycerol sources

\begin{tabular}{ccccc}
\hline Organic Acid & Pure glycerol & BIOCARDEL & BIOLIQ & ROTHSAY \\
\hline Pyruvic acid (mg/L) & 5.6 & 900.00 & 330.00 & 360.00 \\
Glutamic acid (mg/L) & 9.9 & 12.00 & $<1$ & $<1$ \\
$\alpha$-keto-glutaric acid & 105 & 1500.00 & 580.00 & 500.00 \\
(mg/L) & 10 & 43.00 & 210.00 & 200.00 \\
Malic acid (mg/L) & 1.4 & $<1$ & 86.00 & 70.00 \\
Fumaric acid (mg/L) & & & & \\
\hline
\end{tabular}


Table 5: Variation of biomass, lipid, citric acid productivities (g/L/h) and carbon consumption rates $(\mathrm{g} / \mathrm{L} / \mathrm{h})$

\begin{tabular}{|c|c|c|c|}
\hline Pure glycerol & BIOCARDEL & BIOLIQ & ROTHSAY \\
\hline \multicolumn{4}{|c|}{ Biomass productivity (g/L/h) } \\
\hline $8-24 \mathrm{~h}$ & $0-32 \mathrm{~h}$ & $0-24 \mathrm{~h}$ & $0-24 \mathrm{~h}$ \\
\hline $\mathrm{dX} / \overline{\mathrm{dt}=1.74}$ & $\mathrm{dX} / \overline{\mathrm{dt}}=0.72$ & $\mathrm{dX} / \overline{\mathrm{dt}=0.49}$ & $\mathrm{dX} / \mathrm{dt}=0.3$ \\
\hline $\mathrm{R}^{2}=0.95$ & $\mathrm{R}^{2}=0.99$ & $\mathrm{R}^{2}=0.94$ & $\mathrm{R}^{2}=0.99$ \\
\hline$\underline{24-96 ~ h}$ & $\underline{32-96 \mathrm{~h}}$ & $\underline{24-96 ~ h}$ & 24-96 h \\
\hline $\mathrm{dX} / \mathrm{dt}=0.3$ & $\mathrm{dX} / \mathrm{dt}=0.198$ & $\mathrm{dX} / \mathrm{dt}=0.12$ & $\mathrm{dX} / \mathrm{dt}=0.07$ \\
\hline $\mathrm{R}^{2}=0.97$ & $\mathrm{R}^{2}=0.97$ & $\mathrm{R}^{2}=0.94$ & $\mathrm{R}^{2}=0.987$ \\
\hline \multicolumn{4}{|c|}{ Lipid productivity (g/L/h) } \\
\hline$\underline{8-24 \mathrm{~h}}$ & $\underline{8-24 \mathrm{~h}}$ & $8-16 \mathrm{~h}$ & 8-16 h \\
\hline $\mathrm{dL} / \mathrm{dt}=0.25$ & $\mathrm{dL} / \overline{\mathrm{dt}=0.337}$ & 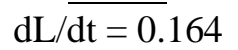 & $\mathrm{dL} / \mathrm{dt}=0.124$ \\
\hline $\mathrm{R}^{2}=0.96$ & $\mathrm{R}^{2}=0.97$ & $\mathrm{R}^{2}=0.97$ & $\mathrm{R}^{2}=0.99$ \\
\hline$\underline{24-64 \mathrm{~h}}$ & $\underline{24-72 ~ h}$ & $\underline{16-96 \mathrm{~h}}$ & $16-96 \mathrm{~h}$ \\
\hline $\mathrm{d} \overline{\mathrm{L} / \mathrm{dt}=0.1}$ & $\mathrm{dL} / \overline{\mathrm{dt}=0.058}$ & $\mathrm{dL} / \overline{\mathrm{dt}}=0.06$ & $\mathrm{dL} / \overline{\mathrm{dt}}=0.03$ \\
\hline $\mathrm{R}^{2}=0.99$ & $\mathrm{R}^{2}=0.98$ & $\mathrm{R}^{2}=0.98$ & $\mathrm{R}^{2}=0.97$ \\
\hline$\underline{64-96 \mathrm{~h}}$ & $\underline{72-96 \mathrm{~h}}$ & & \\
\hline $\mathrm{dL} / \overline{\mathrm{dt}}=0.27$ & $\mathrm{dL} / \overline{\mathrm{dt}}=0.18$ & & \\
\hline $\mathrm{R} 2=0.99$ & $\mathrm{R}^{2}=0.98$ & & \\
\hline \multicolumn{4}{|c|}{ Citric Acid productivity (g/L/h) } \\
\hline$\underline{0-32 \mathrm{~h}}$ & $\underline{0-24 \mathrm{~h}}$ & $\underline{0-24 \mathrm{~h}}$ & $\underline{0-24 \mathrm{~h}}$ \\
\hline $\mathrm{dC} / \overline{\mathrm{dt}=0.028}$ & 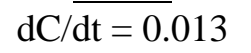 & $\mathrm{dC} / \overline{\mathrm{dt}=0.007}$ & $\mathrm{dC} / \mathrm{dt}=0.12$ \\
\hline $\mathrm{R}^{2}=0.96$ & $\mathrm{R}^{2}=0.99$ & $\mathrm{R}^{2}=0.97$ & $\mathrm{R}^{2}=0.99$ \\
\hline$\underline{40-96 \mathrm{~h}}$ & $\underline{24-48 ~ h}$ & $\underline{24-96 \mathrm{~h}}$ & $\underline{24-80 ~ h}$ \\
\hline $\mathrm{dC} / \overline{\mathrm{dt}=0.018}$ & $\mathrm{dC} / \mathrm{dt}=0.166$ & $\mathrm{dC} / \mathrm{dt}=0.161$ & $\mathrm{dC} / \mathrm{dt}=0.22$ \\
\hline $\mathrm{R}^{2}=0.9$ & $\mathrm{R}^{2}=0.99$ & $\mathrm{R}^{2}=0.987$ & $\mathrm{R}^{2}=0.97$ \\
\hline & $\underline{48-96 \mathrm{~h}}$ & & \\
\hline & $\mathrm{dC} / \mathrm{dt}=0.072$ & & \\
\hline & $\mathrm{R}^{2}=0.97$ & & \\
\hline \multicolumn{4}{|c|}{ Carbon consumption rate $(\mathrm{g} / \mathrm{L} / \mathrm{h})$} \\
\hline $0-48 \mathrm{~h}$ & $0-40 \mathrm{~h}$ & $0-24 \mathrm{~h}$ & $0-24 \mathrm{~h}$ \\
\hline $\mathrm{dS} / \overline{\mathrm{dt}=0.51}$ & $\mathrm{dS} / \overline{\mathrm{dt}=0.797}$ & $\mathrm{dS} / \mathrm{dt}=0.5$ & $\mathrm{dS} / \overline{\mathrm{dt}}=0.37$ \\
\hline $\mathrm{R}^{2}=0.98$ & $\mathrm{R}^{2}=0.99$ & $\mathrm{R}^{2}=0.98$ & $\mathrm{R}^{2}=0.99$ \\
\hline$\underline{48-96 \mathrm{~h}}$ & $\underline{40-96 \mathrm{~h}}$ & $\underline{24-96 \mathrm{~h}}$ & $\underline{24-96 \mathrm{~h}}$ \\
\hline $\mathrm{dS} / \mathrm{dt}=0.19$ & $\mathrm{dS} / \mathrm{dt}=0.33$ & $\mathrm{dS} / \mathrm{dt}=0.2$ & $\mathrm{dS} / \mathrm{dt}=0.10$ \\
\hline $\mathrm{R}^{2}=0.99$ & $\mathrm{R}^{2}=0.96$ & $\mathrm{R}^{2}=0.94$ & $\mathrm{R}^{2}=0.98$ \\
\hline
\end{tabular}

This article is protected by copyright. All rights reserved. 